\title{
Nano-visualization of proteins in action using high-speed AFM
}

\author{
Takayuki Uchihashi, Noriyuki Kodera, and Toshio Ando
}

\section{Abstract}

Direct and real-time visualization of single protein molecules is a powerful approach to understanding how they operate to function. Recent advances of highspeed atomic force microscopy (HS-AFM) provide a new opportunity to visualize dynamic events of label-free proteins in action under physiological conditions, at subsecond to sub-100 ms temporal and submolecular resolution. This chapter first overviews HS-AFM techniques essential for fast and low-invasive imaging of proteins. Then, are highlighted recent imaging studies on myosin $\mathrm{V}$ walking on an actin filament, rotary catalysis of rotorless $\mathrm{F}_{1}$-ATPase, and processive run of cellulase hydrolyzing cellulose fibers.

\section{Introduction}

Dynamic action of proteins, such as their conformational change and dynamic interplay with interaction partners, are crucial to their biological functions. To reveal the dynamic behavior of proteins, single-molecule approaches are indispensable because the molecules behave in an unsynchronized manner and therefore it is difficult to monitor their dynamics by ensemble-average experiments. Fluorescence microscopy has been widely used to study the functional behavior of single protein molecules (Peterman et al., 2004; Joo et al., 2008; Roy et al., 2008; Yanagida and Ishii, 2008). However, it only visualizes featureless fluorescent spots. Moreover, what we can know thereby is only about the behavior of a selected portion of the labeled protein. Namely, protein molecules themselves are invisible in the observations. Therefore, inferences have to be made to bridge the gap between the observed behavior of fluorescent spots and the actual behavior of labeled protein molecules. Consequently, it takes a considerably long time until reaching a persuasive conclusion on how a protein dynamically acts while functioning.

Atomic force microscopy (AFM) (Binnig et al., 1986) has made it possible for the first time to visualize the surface topography of samples at singlenanometer resolution even in liquid environments (Drake et al., 1989; Weisenhorn et al., 1989). In the early stage, pioneering studies explored this new capability by visualizing various biological samples under physiological conditions (Lindsay et al., 1989; Weisenhorn et al., 1989; Hansma et al., 1993; Schabert and Engel, 1994; 
Müller et al., 1995; Shao and Yang, 1995; Walz et al., 1996; Müller and Engel, 1999). Moreover, several groups attempted to visualize dynamic biological processes (Bezanilla et al., 1994; Guthold et al., 1994; Kasas et al., 1997; Lin et al., 1999; Oberleithner et al., 2000). For example, the clotting process of fibrin (Drake et al., 1989), viral infection of isolated cells (Häberle et al., 1992), and antibody binding to an S-layer protein (Ohnesorge et al., 1992) were imaged at $\sim 1$ min or longer intervals. So, in the early stage after the advent of AFM, researchers were already well aware that innovative biological studies would be opened by a new approach, i.e., visualization of dynamic events occurring with biological samples using AFM. In fact, one of the inventers of AFM, Gerd Binnig, mentioned as "In biology, use of the force microscope will probably become quite common because of its ability to deliver films of processes" (Binnig, 1992). Nevertheless, we had to wait long until 2008 for the establishment of the high-speed AFM (HS-AFM) instrumentation (Ando et al., 2008).

Establishing both high-speed and low-invasive performances of AFM required lengthy efforts at solving various technical problems. In the early stage, small cantilevers (Schäffer et al., 1997; Ando et al., 2001), a fast scanner (Ando et al., 2001), a fast amplitude detector (Ando et al., 2001), and an optical beam deflection (OBD) sensor for detecting deflection of a small cantilever (Schäffer et al., 1996; Ando et al., 2001) were developed. Using HS-AFM equipped with some of these devices, fast imaging were attempted to visualize dynamic events of proteins (Viani et al., 2000; Ando et al., 2001). However, it was evident that the bandwidth of feedback control to maintain the tip-sample interaction force constant was not high enough. Then, we further developed smaller cantilevers (Kitazawa et al., 2003; Ando et al., 2008), a faster z-scanner (Fukuma et al, 2008), an active damping technique for the z-scanner (Kodera et al., 2005), a new proportional-integralderivative (PID) feedback controller (Kodera et al., 2006), a compensator for drift in cantilever excitation efficiency (Kodera et al., 2006), and a fast amplitude detector with low noise performance (Ando et al., 2008).

Going through these developments and the proof-of-principle stage, HSAFM has now moved to a new stage where this new microscopy can be used to provide new insights into the functional mechanism of proteins. Various objects and dynamic events have already been imaged by HS-AFM (Table 1). Although only imaged from the top direction, the whole topography of proteins and their minute temporal changes are visualized in some of these studies. Unlike fluorescence microscopy, various dynamic events of a molecule appear in the AFM movie without planned selection, meaning that both expected and unexpected dynamic molecular behaviors can appear simultaneously. Therefore, we can have a great chance of learning details of several facts of molecular action in one imaging experiment. Moreover, the molecular action that appears on video can often be interpreted straightforward without sophisticated analysis, leading to attainment of convincing conclusions. These excellent general features of HS-AFM imaging significantly facilitate and accelerate our understanding of the functional mechanism of proteins. In this chapter we first briefly overview the key techniques for realizing HS-AFM, and then highlight recent representative results on functioning proteins obtained by my group. For more imaging studies, see a recent review (Ando, 2012). 


\section{Overview of High-speed-AFM Instrumentation}

\subsection{Overall Design of HS-AFM System}

Among various operation modes of AFM, our HS-AFM system (Fig. 1) uses the tapping mode in which the cantilever tip is vertically oscillated at the first resonant frequency of the cantilever (Hansma et al., 1993; Zhong et al., 1993; Putman et al., 1994). The intermittent tip-sample contact eliminates the lateral force acting between tip and sample and thus prevents weakly adsorbed proteins from being dislodged from the substrate surface. Upon tip-sample contact, the cantilever oscillation amplitude decreases. During lateral scanning of the sample stage, the change in the amplitude is measured and then the sample stage is moved in the z-direction to recover the amplitude back to a given value (i.e., set point) through feedback control. For fast and nondestructive imaging of biological samples, the feedback control should be performed fast and precisely. Therefore, all devices contained in the feedback loop; $i$. e., the cantilever, the OBD sensor, the amplitude detector, the PID feedback circuit, the piezoactuator-based scanner, and the piezodriver, are optimized for their fast response.

The HS-AFM system includes an original inverted optical microscope. An objective lens with a long working distance used for the optical microscope is a part of the OBD sensor, and is also used for viewing the cantilever and sample stage under the optical microscope, via a digital camera or a CCD camera. A glass slide, to which a cantilever holder and a liquid cell are attached, is placed on the optical microscope stage. A cantilever chip is held in the holder so that its tip points upwards (opposite to the way in conventional AFM). A sample stage attached to the z-scanner and facing downwards is placed over the cantilever. The instrument is now commercially available from the Research Institute of Biomolecule Metrology, Ltd. (Tsukuba, Japan).

\subsection{Small Cantilevers and OBD Sensor}

The cantilevers to be used in HS-AFM should have a high-resonant frequency and a small spring constant to meet both fast and low-invasive imaging capabilities, and thus, should be fabricated to a small size. We use small rectangular cantilevers, so-called beak-like cantilevers, made of silicon nitride (Kitazawa et al., 2003). The dimensions are $\sim 6 \mu \mathrm{m}$ long, $\sim 2 \mu \mathrm{m}$ wide and $\sim 90 \mathrm{~nm}$ thick (BLAC7DS-KU2, custom-made by Olympus). They have resonant frequencies $\sim 3.5$ $\mathrm{MHz}$ in air and $\sim 1.2 \mathrm{MHz}$ in water, a spring constant $\sim 0.2 \mathrm{~N} / \mathrm{m}$, and a quality factor $\sim 2$ in water. Slightly larger cantilevers $(9-10 \mu \mathrm{m}$ long, $2 \mu \mathrm{m}$ wide, and $130 \mathrm{~nm}$ thick; BL-AC10DS, Olympus, Tokyo) with resonant frequencies $1.5 \mathrm{MHz}$ in air and $0.6 \mathrm{MHz}$ in water, a spring constant $0.1 \mathrm{~N} / \mathrm{m}$, and a quality factor $Q \sim 2$ in water are available from Olympus, Atomic Force F\&E GmbH (Mannheim, Germany), Asylum Research (Santa Barbara, USA), and Bruker (Calle Tecate, USA).

The apex of the beak-like tip is not small enough $(25-100 \mathrm{~nm})$ to acquire high-resolution images. We usually use electron-beam-deposited (EBD) tip grown 
on the original beak-like tip using a field emission scanning electron microscope (FE-SEM) (Wendel et al., 1995). As a sublimate for the EBD tip, phenol powder is used. A spot-mode electron beam is focused onto each original tip to produce a $\sim 1 \mu \mathrm{m}$ long needle composed of amorphous carbon at a growth rate of $\sim 17 \mathrm{~nm} / \mathrm{s}$. The EBD tip is sharpened by oxygen or nitrogen plasma etching to an apex radius of $\sim 4 \mathrm{~nm}(\sim 0.5 \mathrm{~nm}$ at the best case).

In our OBD sensor (Ando et al., 2001), an incident laser beam is focused onto a small cantilever through a $\times 20$ objective lens with a long working distance $24 \mathrm{~mm}$ (Fig.1). The light reflected back from the rear side of the cantilever is collected and collimated using the same objective lens and guided to a quadrant-cell Si PIN photodiode. The focused spot is $3-4 \mu \mathrm{m}$ in diameter. The incident and reflected beams are separated using a quarter wavelength plate and a polarization beam- splitter. The small cantilevers provide the OBD sensor with high deflection detection sensitivity (10-20 times higher than conventional large cantilevers) because the angle change at the cantilever's free end is 10-20 times larger for a given vertical displacement of the tip.

\subsection{Amplitude Detector and Feedback Controller}

The oscillation amplitude of the cantilever should be detected as fast as possible with a high signal-to-noise ratio. A conventional RMS-to-DC converter and a lock-in amplifier require at least several oscillation cycles to output an accurate amplitude signal. We developed two types of fast amplitude detectors, a peakhold type (Ando et al., 2001) and a Fourier type (Kokavecz et al., 2006; Ando et al., 2008). In the peak-hold analogue circuit, the peak and bottom voltages of the output signal from the OBD senor are held and their difference is output as an amplitude signal. The amplitude signal is renewed every half cycle of cantilever oscillation. In the Fourier type (analogue/digital hybrid system), Fourier cosine and sine coefficients $\left(a_{1}, b_{1}\right)$ are calculated every one cycle of cantilever oscillation and a signal proportional to $\left(a_{1}^{2}+b_{1}^{2}\right)^{1 / 2}$ is output. The Fourier method is less susceptible to cantilever's thermal fluctuations in the deflection than the peak-hold method.

For the feedback control under a small tapping force condition, the amplitude set point should be set close to the free oscillation amplitude of the cantilever. Under this condition, tip 'parachuting' often occurs and thus the error signal is saturated at a small value for a while. 'Parachuting' means that the cantilever tip completely detaches from the sample surface at a steep down-hill region of the sample and time elapses until the tip lands on the surface again. To reduce or eliminate the parachuting time, we developed a dynamic PID controller in which the gain parameters are dynamically changed depending on the cantilever oscillation amplitude (Kodera et al., 2006). This dynamic PID controller can maintain the feedback bandwidth at a high level even when the amplitude set point is close to the cantilever free oscillation amplitude, making high-speed imaging compatible with low-invasive imaging. In addition, an electronics developed to compensate for the drift in the cantilever excitation efficiency allows stable imaging under the small tapping force condition (Kodera et al., 2006). 


\subsection{Scanner and Active Damping}

We developed three types of scanners with different maximum scan ranges. Type-1: $\mathrm{x}=1 \mu \mathrm{m}, \mathrm{y}=4 \mu \mathrm{m}, \mathrm{z}=1 \mu \mathrm{m}$; Type- $2: \mathrm{x}=5 \mu \mathrm{m}, \mathrm{y}=5 \mu \mathrm{m}, \mathrm{z}=2 \mu \mathrm{m}$; and Type-3: $\mathrm{x}=40 \mu \mathrm{m}, \mathrm{y}=40 \mu \mathrm{m}, \mathrm{z}=6 \mu \mathrm{m}$. Type-1 is used for dynamic imaging of isolated proteins, while the latter two types are used for dynamic imaging of larger objects such as bacteria and eukaryotic cells. Each type of scanner is composed of three piezoactuators that displaces the sample along the $\mathrm{x}-, \mathrm{y}-$, and $\mathrm{z}$-axes. The slowest $\mathrm{y}$-scanner displaces a block of the $\mathrm{x}$ - and $\mathrm{z}$-scanners, the $\mathrm{x}$-scanner displaces a block of the z-scanner and the z-scanner displaces a glass-rod sample stage. Each block is connected with the surrounding base through a pair of flexures to achieve small crosstalk between the three displacement axes (Ando et al., 2008). Since the x-piezo is sandwiched between two flexures, the center of mass of the x-piezo is unchanged, minimizing impulsive force exerting to the surrounding base and thus minimizing induction of vibrations. To counteract the impulsive force produced by the z-scanner displacement, two identical piezoactuators are attached to a supporting base and are displaced simultaneously with the same length in the opposite direction (Ando et al., 2001). For the fastest z-scanner with a first resonant frequency $370 \mathrm{kHz}$, a piezoactuator is held at the four rims parallel to the displacement direction in order to counteract the impulsive force (Fukuma et al., 2008).

The first resonant frequencies of the z-scanners are those of the actuators used, meaning that resonance arising from the designed structure occurs at higher frequencies. We developed an active damping technique to eliminate the resonant vibrations of the z-scanners using a new Q-controller with corresponding mock zscanners comprised of LRC circuits (Kodera et al., 2005).

\subsection{Highest Possible Imaging Rate}

As a consequence of the whole development described above, we have achieved the highest feedback bandwidth $f_{\mathrm{B}} \sim 110 \mathrm{kHz}$. This is at least 10-times higher than other nominal high-speed AFM instruments. The highest possible imaging rate $R_{\max }$ is a function of $f_{\mathrm{B}}$, the scan range in the x-direction $W$, the number of scan lines $N$, the smallest sample surface corrugation to be observed $\lambda$, and the sample fragility (Ando et al., 2008; Ando, 2011). The overall relationship can be expressed as

$$
R_{\max }=2 \lambda f_{\mathrm{B}} \theta_{\mathrm{m}} /(\pi W N),(1)
$$

where $\theta_{\mathrm{m}}$ represents an sample fragility-dependent allowable maximum phase delay in tracing the sample surface. Even for relatively fragile molecules $\left(\theta_{\mathrm{m}}<\right.$ $\sim 20^{\circ}$ ), we can capture images at 12 frames/s (fps) under the condition of $W=200$ $\mathrm{nm}, \mathrm{N}=100$, and $\lambda=10 \mathrm{~nm}$ without disturbing the physiological function of the molecules. .

\section{Imaging of Protein Molecules in Action}


Some HS-AFM movies showing the dynamic behavior of proteins described below can be seen at http://www.s.kanazawa-u.ac.jp/phys/biophys/index.htm or at the corresponding publishers' homepages.

\subsection{Myosin V}

\subsubsection{General Properties of Myosin V}

Myosin V (M5) is a two-headed molecular motor that transports intracellular vesicles along actin filaments from the central regions of cells to the periphery (see a review; Sellers and Weisman, 2008). Each N-terminal motor domain containing actin-binding and ATP hydrolysis sites is connected to an extended neck with six calmodulins (or five calmodulins and a light-chain). The region containing the motor and neck domains is called "head". After the neck region, M5 is dimerized by a coiled-coil tail which is followed by a C-terminal globular tail domain capable of binding to various cargos via adapter proteins (Fig. 2a). In order to elucidate the functional mechanism of M5, numerous studies have been done using biophysical and biochemical techniques. Using fluorescence microscopy and optical tweezers, it has been demonstrated that the single molecules move processively along actin filaments towards the plus ends of the filaments (Mehta et al., 1999; Sakamoto et al., 2000) in a hand-over-hand fashion (Forkey et al., 2003; Yildiz et al., 2003) with a 36-nm step for every ATP hydrolysis cycle (Sakamoto et al., 2008). Here, "hand-over-hand" means that the two heads alternate the leading and trailing positions at each step, very analogous to "walking". However, the protein molecules themselves are invisible in the observations and have therefore been visualized by electron microscopy only in the stationary states (Walker et al., 2000; Burgess et al., 2002; Oke et al., 2010). Thus, a comprehensive description of the molecule in action has not been accomplished until our recent HS-AFM study (Kodera et al., 2010). We describe below the outline of the results.

\subsubsection{Unidirectional Hand-over-hand Movement}

As a substrate, we used a mica-supported lipid bilayer composed of an electrically natural phospholipid, a biotinylated phospholipid, and a positively charged phospholipid. The bilayer is in a gel-phase at room temperature (Yamamoto et al., 2010). Partially biotinylated actin filaments were immobilized on the surface through streptavidin molecules with a low surface density (Fig. 2b). The positively charged lipid facilitated observing the characteristic sideways configuration of moving M5, allowing us to acquire high resolution images. The successive AFM images captured at $7 \mathrm{fps}$ in the presence of ATP (Fig. 3a) shows M5-HMM (tailtruncated M5, bottom in Fig. 2a) moving processively along an actin filament with discrete $\sim 36-\mathrm{nm}$ steps. The two-headed bound M5-HMM showed unique structural features without exception, as illustrated in the bottom of Fig. 3a; the neckmotor domain junction appears smooth in the leading head whereas it is V-shaped in the trailing head, because the neck regions emerge from different parts of the motor domain. The short coiled-coil tail was mostly tilted towards the direction 
opposite to the moving direction. These features are totally consistent with those shown in electron micrographs (Walker et al., 2000), and can be used to determine the actin polarity when bound M5-HMM is stationary. However, the AFM movie could not resolve detailed stepping behaviors because the step completed within a frame.

To slow down the step motion, we additionally attached streptavidin molecules on the substrate surface as moderate obstacles to the advance, which successfully allowed us to directly visualize the detailed molecular processes during a step (Fig. 3b). After trailing head detachment from actin, the nearly straight leading head appeared to spontaneously swing from the reverse arrowhead orientation toward the arrowhead orientation, irrefutably showing for the first time the swinging lever-arm motion initially proposed for muscle myosin (Huxley, 1969). The detached trailing head rotationally diffused around the advancing neck-neck junction and then bound to a frontward actin site as a new leading head, completing one step. Thus, the detailed molecular behavior during hand-over-hand movement was directly visualized at unprecedented high spatiotemporal resolution. In the AFM movie, we did not observe other behaviors of M5-HMM expected from the "inchworm" (Hua et al., 2002) model proposed for kinesin and the "biased diffusion" (Okada et al., 2007) model proposed for myosin, at least with the temporal resolution used.

\subsubsection{Tension Generation and Foot Stomp}

The seemingly spontaneous rotation of the leading head following trailing head detachment suggests that intramolecular tension for the advance has already existed in the two-headed bound molecule. In this bound state, the trailing head is in the arrowhead orientation. This orientation is natural one at least for the ADPbound and nucleotide-free myosin heads, and hence, the intramolecular tension is not produced by the bound trailing head. On the other hand, the leading head is not in the natural orientation (i.e., in the reverse arrowhead orientation) and hence pays energy cost to generate the intramolecular tension. In fact, the bound leading head is slightly curved outwards while the trailing head is straight (Fig. 3a). Upon trailing head detachment, the constraint keeping the bound leading head in the unnatural orientation is removed and hence the leading head spontaneously rotates forwards, meaning that the bound leading head is in the strained pre-stroke state and thus the lever arm swing is not accompanied by chemical transitions. This inferred view was reinforced by the observation that the short coiled-coil of twoheaded bound M5-HMM was sometimes unfolded and then the leading head rotated from the reverse arrowhead orientation to the arrowhead orientation (Fig. $4 a)$, very much similar to the swinging lever arm motion observed as powerstroke in the hand-over-hand movement.

In general, during the actomyosin ATPase cycle, the strained pre-stroke state has been thought to be always formed through Pi release from an ADP-Pi bound head weakly interacting with actin (Goldman, 1987; Geeves and Holmes, 1999). Thus, it may be considered that the strained pre-stroke state, which is formed directly by the binding of ADP-bound leading head to actin, does not participate in the forward step in ATP. However, we observed a molecular behavior 
in ATP that indicates that it does participate. In two-headed bound M5-HM, both of the motor domains frequently exhibited brief dissociation and reassociation on the same actin filament (or a brief translocation by around $\pm 5 \mathrm{~nm}$ along the actin filament), whereas M5-HMM remained at approximately the same position on the filament (Fig. 4b). We have termed this behavior "foot stomp". The briefly detached leading head does not carry bound Pi because Pi is already released from an ADP-Pi-bound M5 head immediately after its initial binding to actin (De La Cruz et al., 1999). This immediate release of Pi is a general feature of the actomyosin ATPase reaction. Nevertheless, the detached leading head with only ADP bound rebinds to actin, still in the reverse arrowhead orientation, and then swings forward following trailing head detachment. The detachment of leading head during foot stomp is not caused by ATP binding to the leading head. As described latter, a nucleotide-free leading head is often sharply bent. We never observed a sharply bent leading head before its foot stomp.

\subsubsection{Mechanism for Hand-over-hand Movement}

The leading head of two-headed bound M5-HMM was always straight (slightly curved outwards) in ADP or ATP, while it was often sharply bent in the nucleotide-free condition (Fig. 4c). Therefore, just by looking at the conformation of leading head, we can judge whether or not the leading head contains nucleotides. To estimate the ADP dissociation rate constant at the leading head, M5HMM bound to actin in various concentrations of ADP was observed, and then, the lifetime of straight leading head was analyzed as a function of ADP concentration. The ADP dissociation rate constant at the leading head was estimated to be $0.1 / \mathrm{s}$. This means that ADP is released from the leading head every $10 \mathrm{~s}$, on average. However, M5-HMM walks many steps for $10 \mathrm{~s}$, meaning that ADP does not dissociate from the leading head. That is, before ADP dissociation, the leading head is switched to the trailing head during walking. ADP dissociation, and the subsequent ATP binding, and the resulting detachment from actin solely occurs at the trailing head. This is the basis underlying the processive hand-over-hand movement. This mechanism was inferred previously from various indirect experiments (Rosenfeld and Sweeney, 2004; Purcell et al., 2005; Veigel et al., 2005; Forgacs et al., 2008; Oguchi et al., 2008; Sakamoto et al., 2008) but is now clearly and directly demonstrated by the high-speed AFM observation. Moreover, we found that the foot stomps occurred more frequently at the leading head than at the trailing head. This asymmetry of foot stomp frequency between the two heads suggests that the leading head would be less susceptible to the catalytic activation by actin, which might contribute to some extent to the kinetic asymmetry between the two-heads.

\subsection{Rotary Catalysis of Rotorless $F_{1}$-ATPase}

\subsubsection{General Properties and Cooperativity of $F_{1}$-ATPase}


ATP synthase, which is one of the most abundant proteins in organisms, synthesizes ATP from ADP and Pi using the electrochemical energy of proton gradient across membranes (Boyer, 1993, 1997). It consists of two coupled rotary motors, called $F_{o}$ and $F_{1} . F_{o}$ is embedded in membranes while water-soluble $F_{1}$ is exposed to the solution. They can be separated and studied individually. $F_{1}$ is comprised of five different subunits with a composition of $\alpha_{3} \beta_{3} \gamma \delta \varepsilon$ (Todd et al., 1980; Walker et al., 1985). The three $\alpha$ and $\beta$ subunits are arranged alternately to form a hexameric ring and the central cavity of the hexamer is occupied by the $\gamma$ subunit. The minimum rotary unit of $F_{1}$ is the $\alpha_{3} \beta_{3} \gamma$ subcomplex, in which the central $\gamma$ shaft rotates within the $\alpha_{3} \beta_{3}$ stator ring when ATP is hydrolyzed by the ring (Matsui and Yoshida, 1995). The catalytic site of $F_{1}$ is formed at the interface between the $\alpha$ and $\beta$ subunits. The catalytic residues mainly reside in the $\beta$ subunit (Abrahams et al., 1994). The rotational motion of $\gamma$ has been demonstrated by single-molecule optical microscopy in which optical markers are attached to the $\gamma$ subunit (Noji et al., 1997; Yasuda et al., 1998).

In the earliest obtained crystal structure shown in Fig. 5a, three catalytic sites are in different nucleotide-bound states; one binds to an ATP analog $\left(\beta_{\text {TP }}\right.$ and $\left.\alpha_{\mathrm{TP}}\right)$, another binds to ADP ( $\beta_{\mathrm{DP}}$ and $\left.\alpha_{\mathrm{DP}}\right)$, and the third binds to none ( $\beta_{\mathrm{E}}$ and $\left.\alpha_{\mathrm{E}}\right)$. Both $\beta_{\text {TP }}$ and $\beta_{\mathrm{DP}}$ swing the C-terminal domain toward $\gamma$, assuming an inwardly retracted conformation, whereas $\beta_{\mathrm{E}}$ swings the domain away from $\gamma$, assuming an outwardly extended conformation. Because the two conformational states seem to push $\gamma$ or be pushed by $\gamma$ as shown in Fig. 5b and c, it was considered that the $\beta-\gamma$ interaction controls the conformational and catalytic states of individual $\beta$ subunits and thus is essential for sequential torque generation (Wang and Oster, 1998). Some biochemical studies are considered to suggest that the $\alpha_{3} \beta_{3}$ ring alone does not possess intrinsic cooperativity and $\gamma$ mediates interplays among $\beta$ 's (Kaibara et al., 1996; Capaldi, 1998; Nakamoto et al., 1999). On the other hand, although very few, there are biochemical studies which suggest that the intrinsic cooperativity is engendered by the $\alpha_{3} \beta_{3}$ ring alone (Yoshida and Allison, 1990; Aloise et al., 1991).

Recently, it was reported that even when the most interaction sites between $\beta$ and $\gamma$ are abolished, the $\gamma$ still rotates unidirectionally (Hossain et al., 2006, 2008; Furuike et al., 2008) . However, single-molecule optical microscopy does not allow us to directly examine whether the intrinsic cooperativity in the $\alpha_{3} \beta_{3}$ ring is the core responsible for sequential torque generation since attachment of a probe to the rotary shaft is required for visualization. We addressed this issue by directly imaging the ATP-driven conformational transition of $\beta$ 's in the isolated $\alpha_{3} \beta_{3}$ ring using high-speed AFM (Uchihashi et al., 2011).

\subsubsection{AFM Observation of $\alpha_{3} \beta_{3}$ Subcomplex without ATP}

The $\alpha_{3} \beta_{3}$ subcomplex with Lys $_{7}$-tag at the N-terminus of $\beta$ was covalently immobilized on a mica surface treated first with 3-aminopropyl-triethoxysilane and then with glutaraldehyde. Therefore, the C-terminal domain of the $\alpha_{3} \beta_{3}$ subcomplex is at the top side. As shown in Fig. 6a, a ring structure with six high protrusions was observed under the nucleotide free conditions. Fig. $6 \mathrm{~b}$ shows an averaged high-resolution image of the $\alpha_{3} \beta_{3}$ subcomplex without nucleotide. This 
image shows a pseudo-six-fold symmetric ring in which three subunits alternately arranged in the ring are higher than the other three. The simulated AFM image of the C-terminal side of the ring constructed from the crystal structure of nucleotidefree $\alpha_{3} \beta_{3}$ subcomplex (Shirakihara et al., 1997) well reproduced the observed image (Fig. 6c), indicating that the N-terminal side was in fact selectively attached to the mica, although a smaller crown corresponding to the $\mathrm{N}$-terminal side was occasionally observed (Fig. 6d). The image was similar to a simulated image (Fig. $6 \mathrm{e})$. Three $\beta$ 's, all assuming the outwardly extended conformation in the crystal structure of the $\alpha_{3} \beta_{3}$, gave three protrudent peaks in the simulated image as bright spots and thus the three subunits showing higher protrusions seen in the AFM image were identified as $\beta$ 's.

When AMPPNP, which is a non-hydrolyzable ATP analog, was added, the ring became triangular and the central hole was obscure as shown in Fig. 6f. Three $\alpha$ 's having the lower protrusions retained the same conformation as those under the nucleotide-free condition and two of the three $\beta$ 's retracted towards the center and at the same time lowered their protrusions. This structure did not change during the observation. A simulated image of $\alpha_{3} \beta_{3}$ with bound nucleotides (Fig. 6h) which was constructed using the crystal structure (Abrahams et al., 1994) of $F_{1}$ without $\gamma$ (Fig. 6g) showed an asymmetric ring very similar to the observed image. This excellent agreement indicates that only two $\beta$ 's can assume the inwardly retracted conformation even in saturating AMPPNP, which is consistent with the previous observation that three $\beta$ 's do not assume the inwardly retracted conformation simultaneously (Menz et al., 2001).

\subsubsection{HS-AFM Observation of $\alpha_{3} \beta_{3}$ Subcomplex in ATP}

In the presence of ATP, the ring shape was very similar to that observed in the presence of AMPPNP but the ring showed distinct conformational dynamics; each $\beta$ underwent conformational transition between the outwardly extended high state (O-state) and the retracted low state (C-state) (Fig. 7a); the outwardly extended and inwardly retracted conformations are well correlated with the high and low protrusion states, respectively (Fig. 7b). Prominent features observed are that when the O-to-C transition occurs at one $\beta$, the opposite C-to-O transition occurs simultaneously at its counterclockwise neighbor $\beta$ in most cases as shown in Fig. $7 \mathrm{a}$. By this cooperative effect, the $\mathrm{CCO}$ conformational state propagates in the counterclockwise direction as seen in the time evolution of the cumulated angle of the open- $\beta$ position relative to the center of the ring (Fig. $7 \mathrm{c}$ ).

The rate of rotational propagation of the $\mathrm{CCO}$ conformational state increased with increasing ATP concentration $(2-4 \mu \mathrm{M})$, indicating that ATP binding is ratelimiting. The rate constant of the counterclockwise O-to-C shift in $\beta$ at each ATP concentration was comparable with the corresponding initial rate of ATP hydrolysis measured biochemically. Thus, ATP hydrolysis is well coupled with the O-to$\mathrm{C}$ transition of $\beta$.

The interplay between $\beta$ subunits in $\alpha_{3} \beta_{3}$ responsible for the rotational propagation of the CCO conformational state was further supported by the following observation. A single subunit was occasionally dissociated from $\alpha_{3} \beta_{3}$ during observation (Fig. 7d), due presumably to the imperfect covalent binding of the 
subcomplex to the mica surface and to transient strong tip-sample interaction. Once one $\beta$ is lost, the rotary propagation completely ceased (Fig. 7e), although some cooperative conformational transitions occurred between the remained $\beta$ 's.

These results provide clear evidence that the structural basis of unidirectional rotary catalysis is intrinsically programmed in the stator ring. Thus, the " $\gamma$ dictator" model (Furuike et al., 2008), which proposes that only the interaction with $\gamma$ determines the conformational and catalytic states of $\beta$ 's (Adachi et al., 2007; Watanabe et al., 2010), is not valid. On the other hand, the ATP-binding rate and the efficiency of unidirectionality of the $\mathrm{CCO}$ state propagation are distinctly lower than those of $F_{1}$ (Uchihashi et al., 2011). Thus, the interaction with $\gamma$ is dispensable but still important for the rapid and precise rotary catalysis. Our findings are not inconsistent with the observations that the rate of the catalytic reaction are apparently under the control of the rotary angle of $\gamma$ (Itoh et al., 2004; Rondelez et al., 2005; Iko et al., 2009). The intrinsic interplay among $\beta$ 's would reinforce the catalytic control by $\gamma$; even if $\gamma$ tightly interacts with only one $\beta$, it still can act on all $\beta$ 's through $\beta-\beta$ interplay.

\subsection{Processive movement and traffic jams of cellulase on cellulose surface}

\subsubsection{Genral Issues of Cellulose Hydrolysis by Cellulase}

Cellulase, which is produced mainly by cellulolytic fungi and bacteria, is a group of enzymes that degrade the plant polysaccharide called cellulose, a linear polymer connected by $\beta-1,4$ linkages (Ryu and Mandels, 1980; Hon, 1994). Although all types of cellulases can hydrolyze amorphous cellulose, only a limited number of cellulases can hydrolyze crystalline cellulose (Teeri, 1997). The enzymes that hydrolyze crystalline cellulose are called cellobiohydrolases (CBHs) because the major product of the reaction is cellobiose, a soluble $\beta$-1,4-glucosidic dimer (Teeri et al., 1998) . CBHs share a similar two-domain structure consisting of a catalytic domain (CD) and a cellulose-binding domain (CBD) (Abuja et al., 1988a; Abuja et al., 1988b; Abuja et al., 1989). The two domains are connected by a highly $O$-glycosylated linker region (Rouvinen et al., 1990; Divne et al., 1994, 1998). At the initial step of the reaction, the cellulase enzymes adsorb onto the surface of crystalline cellulose via the CBD, and then glucosidic linkages are hydrolyzed by the CD (Johansson et al., 1989; Ståhlberg et al., 1991). Loss of the CBD causes a significant decrease of crystalline cellulose degradation, but has a less effect on the hydrolysis of soluble or amorphous cellulose, suggesting that adsorption of the enzymes on the surface via the CBD is essential for the effective hydrolysis of crystalline cellulose (Ståhlberg et al., 1991). The CD has a relatively long tunnel formed by surface loops with catalytic amino acids extending from the central fold of the CD. A cellulose chain threads through the tunnel and is hydrolyzed (Divne et al., 1994, 1998). Therefore, it has been considered that CBHs hydrolyze crystalline cellulose chains in a processive manner, making consecutive cuts without releasing the chain (Davies and Henrissat, 1995; Reverbel-Leroy et 
al., 1997), but this idea has not been experimentally verified until recent HS-AFM imaging studies (Igarashi et al., 2009, 2011). The CBHs are categorized into two main types; CBH I hydrolyzes cellulose from the reducing end of cellulose, while $\mathrm{CBH}$ II does from the nonreducing end (Henrissat and Bairoch, 1993). The CD of $\mathrm{CBH}$ I belongs to the glycoside hydrolase $(\mathrm{GH})$ family 7 and the $\mathrm{CD}$ of $\mathrm{CBH}$ II belongs to the GH family 6 .

Although the kinetics of crystalline cellulose hydrolysis by CBHs has thus far been investigated intensively, the mechanism of crystalline cellulose degradation by $\mathrm{CBHs}$ is still elusive. For example, although it is known that the hydrolysis rate decreases rapidly with time (Eriksson et al., 2002), its mechanism has not yet been understood. Furthermore, several studies indicate that CBH I and CBH II types of enzymes display strong synergy for the hydrolysis of cellulose (Henrissat et al., 1985; Boisset et al., 2000) but the reason for the synergy effect is not yet revealed. The main reason for the difficulty in understanding these issues is the lack of analytical methods to monitor the enzymatic reaction at the solid/liquid interface.

\subsubsection{Processive Run of Cellulase on Cellulose $I_{\alpha}$}

The dynamic behavior of CBHs on a crystalline cellulose substrate were visualized using HS-AFM (Igarashi et al., 2009, 2011). We first observed a CBH I ( $\operatorname{Tr}$ Cel7A) secreted from the industrially important cellulolytic ascomycete fungus Trichoderma reesei. $\operatorname{TrCel7A}$ is one of the best-studied CBHs (Abuja et al., 1989; Henrissat, 1991; Henrissat and Bairoch, 1993; Divne et al., 1994; Linder, 1997; Henrissat et al., 1998; Boraston et al., 2004). We used a crystalline cellulose prepared from the cell wall of green algae, which consists of mainly cellulose $\mathrm{I}_{\alpha}$ (Hon, 1994). As a substrate surface, we chose highly ordered pyrolytic graphite (HOPG) because its hydrophobic surface has a high affinity for the hydrophobic surface of the crystalline cellulose. Fig. 8a shows HS-AFM images of $\operatorname{TrCel7A}$ molecules moving unidirectionally and processivly on the cellulose $I_{\alpha}$ surface. This movement of $\operatorname{TrCel7A}$ was observed only on the top surface of the cellulose crystal where the individual molecules were moving in a line. Interestingly, as shown in Fig. 8b, the movement of molecules was often halted due probably to the presence of an obstruction on the crystalline cellulose surface. When the movement of a molecule was halted, following molecules were blocked and/or slowed down (Igarashi et al., 2011). These phenomena resemble the movement of traffic on a road.

To evaluate the velocity of the movement, we tracked the center of each molecule. Fig. 8c shows the time courses of displacement for seven molecules. Some molecules move continuously without stopping, whereas the movement of some molecules were occasionally halted or slowed down (the open green and closed red plots in Fig. 8c). Fig. 8d shows a histogram of the measured velocity values. The histogram is comprised of two Gaussian distributions of the average velocity with mean \pm SD values of $-0.32 \pm 3.4$ and $7.1 \pm 3.9 \mathrm{~nm} / \mathrm{s}$. This is consistent with the idea that $\operatorname{Tr} \mathrm{Cel} 7 \mathrm{~A}$ has two modes of adsorption on a cellulose surface; the productive adsorption mode in which both CD and CBD contribute to the binding and the non-productive adsorption mode in which the enzyme binds only via the CBD (Ståhlberg et al., 1991). The overall average velocity for many mole- 
cules was $5.3 \pm 4.9 \mathrm{~nm} / \mathrm{s}$. From the velocity, the hydrolysis rate is estimated to be $5 / \mathrm{s}$ taking into account that one hydrolysis drives the movement of the molecule by $1 \mathrm{~nm}$ which is the length of cellobiose. Surprisingly, this value is 500 times larger than that $(0.01 / \mathrm{s})$ estimated biochemically (Nidetzky et al., 1994). This inconsistency is presumably because in the biochemical estimation of the hydrolysis rate, it is assumed that all molecules productively work on the cellulose surface. However, the number of reduced ends available for $\operatorname{TrCel7A}$ binding is limited and moreover the movement of many molecules is hampered by the traffic jams.

\subsubsection{Processive Run of Cellulase on Cellulose IIII}

The fabric form of cellulose $\mathrm{I}_{\alpha}$ can be converted to cellulose $\mathrm{III}_{\mathrm{I}}$ polymorph by supercritical ammonia treatment (Igarashi et al., 2007). Although it is known that this conversion dramatically enhances the cellulose hydrolysis by $\operatorname{Tr} \mathrm{Cel} 7 \mathrm{~A}$ (Igarashi et al., 2007), its mechanism has been unknown. We investigated this is-

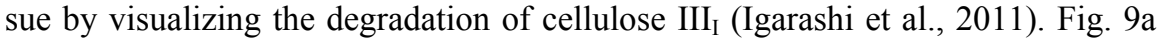
shows successive images of $\operatorname{Tr}$ Cel7A molecules processively moving on a cellulose $\mathrm{III}_{\mathrm{I}}$ surface. The number of molecules on the cellulose $\mathrm{III}_{\mathrm{I}}$ surface appears larger than that on the cellulose $I_{\alpha}$ surface shown in Fig. 9a although the velocity of the molecules on both surfaces are similar. In the case of cellulose $I_{\alpha}$, the molecules only slid along limited lanes, whereas on cellulose $\mathrm{III}_{\mathrm{I}} \operatorname{Tr}$ Cel7 A molecules moved over almost the whole exposed surface. This is due probably to the difference of affinity for $\operatorname{Tr}$ Cel7A between cellulose $\mathrm{I}_{\alpha}$ and $\mathrm{III}_{\mathrm{I}}$. Comparing the crystalline shapes of cellulose $\mathrm{I}_{\alpha}$ and $\mathrm{III}_{\mathrm{I}}$ (Nishiyama et al., 2003; Wada et al., 2004), cellulose $I_{a}$ has a hydrophobic surface (where the enzyme molecule can bind) at (110) surface (Fig. 9c), whereas cellulose $\mathrm{III}_{\mathrm{I}}$ has a hydrophobic surface not only at (110) surface but also at (100) surface as shown in Fig. 9d. Therefore, cellulose $\mathrm{III}_{\mathrm{I}}$ has more lanes available for cellulase movement and thus causes less traffic jams. This is the mechanism underlying the enhanced degradation of cellulose $\mathrm{III}_{\mathrm{I}}$.

The traffic jams occurring on cellulose $\mathrm{III}_{\mathrm{I}}$ showed a unique feature that did now appear on cellulose $I_{\alpha}$. After several additional molecules were blocked, the enzyme molecules started to move again on the surface and at the same time a cellulose bundle was peeled off from the crystalline cellulose as shown in Fig. 9b. This phenomenon suggests that one enzyme molecule is unable to overcome an obstacle to the advance but accumulation of molecules behind the blocked molecule overcomes the obstacle. As a result, the blocked molecules re-start linear movement from the point where the first molecule had stopped.

\subsubsection{Synergetic Hydrolysis by TrCel7A and TrCel6A}

As shown in Fig. 10a, two major CBHs, $\operatorname{Tr}$ Cel7A and $\operatorname{Tr}$ Cel6A synergistically increase the efficiency of cellulose $\mathrm{III}_{\mathrm{I}}$ hydrolysis. This effect has been called exo-exo synergy (Nidetzky et al., 1994). Previous transmission electron microscopic observations of a crystalline cellulose after partial hydrolysis by both $\operatorname{Tr} \mathrm{Cel6 \textrm {A }}$ and $\operatorname{Tr} \mathrm{Cel}$ 7A showed that the two enzymes degrade the cellulose from different ends of the crystal; $\operatorname{Tr} \mathrm{Cel}$ 7A degrades the crystal from the reducing end, leading to fibrillation, thinning of the crystal, or narrowing of the crystal end, whe- 
reas $\operatorname{Tr}$ Cel6A hydrolyzes the crystal from the non-reducing end, less processively than $\operatorname{Tr}$ Cel7A, thereby sharpening the crystal tip (Chanzy and Henrissat, 1985; Imai et al., 1998). It is however difficult to explain this type of synergistic action based on their exoenzymatic activity. We imaged the hydrolytic process with crystalline cellulose $\mathrm{III}_{\mathrm{I}}$ in the presence of both $\operatorname{Tr} \mathrm{Cel} 6 \mathrm{~A}$ and $\operatorname{Tr} \mathrm{Cel} 7 \mathrm{~A}$ to understand the mechanism underlying the synergetic degradation (Igarashi et al., 2011).

Cellulose $\mathrm{III}_{\mathrm{I}}$ was first imaged in the presence of $\operatorname{Tr} \mathrm{Cel} 6 \mathrm{~A}$ alone. The appearance of the cellulose crystals did not significantly change during incubation over $\sim 8 \mathrm{~min}$, even though many enzyme molecules were observed on the cellulose surfaces (Fig. 10b). After $\operatorname{Tr}$ Cel7A was additionally added, enzyme molecules started moving from many points on the cellulose surfaces, and the degradation of crystalline cellulose was dramatically faster than the case with $\operatorname{Tr}$ Cel7A alone as shown in Fig. 10c. Eventually, the cellulose crystals almost disappeared at $\sim 4$ min after the addition of $\operatorname{Tr}$ Cel7A. The observed synergy was independent of the order of addition of $\operatorname{Tr} \mathrm{Cel} 6 \mathrm{~A}$ and $\operatorname{Tr} \mathrm{Cel} 7 \mathrm{~A}$. A very similar synergy effect was also observed when both $\operatorname{Tr}$ Cel6A and $\operatorname{Tr}$ Cel7A were added simultaneously. These results suggest that $\operatorname{Tr} \mathrm{Cel} 6 \mathrm{~A}$ is also an endoenzyme and the synergy observed is therefore endo-exo synergy (Wood and McCrae, 1978), although $\operatorname{Tr} \mathrm{Cel6A}$ is generally defined as an exo-glucanase (cellobiohydrolase). If so, $\operatorname{Tr}$ Cel6A generates nicks in the middle of crystalline cellulose, and these nicks become starting and ending points for $\operatorname{Tr}$ Cel7A activity.

The present results provide us with some clues to improving the efficiency of conversion from crystalline cellulose to cellobiose by cellulase enzymes. The following devices will certainly improve the conversion efficiency; flattening the surface of crystalline cellulose to remove obstacles to the advance of the enzymes; increasing the number of lanes by means of pretreatment of cellulose; combining exo- and endo-cellulase enzymes to increase the number of entrances and exits for the exoenzymes.

\section{Concluding Remarks}

Through the instrument development and proof-of-principle stages, HSAFM is now established and can be used to visualize dynamic processes and structure dynamics of proteins and other biological molecules. This capability allows us to visually and directly understand how biomolecules operate to function. As demonstrated by the three recent results highlighted in this chapter, HS-AFM can provide unique new insights into the functional mechanism of proteins unattainable with previous single-molecule techniques.

Other than the examples describe here, our HS-AFM instrument has already been applied to studying dynamics of various samples (Table 1); for instances, alternate binding of GroES to the two rings of GroEL (Yamamoto et al., 2009), dynamics of protein 2D crystals (Yamamoto et al., 2008; Yamashita et al., 2009), wiggling motion of intrinsically disordered regions of FACT protein (Miyagi et al., 2008), photo-induced conformational change of bacteriorhodopsin (Shibata et al., 
2010, 2011) and so on. The HS-AFM apparatuses commercialized by RIBM (Tsukuba, Japan) have been used to study various targets (Yokokawa et al., 2006a, 2006b; Crampton et al., 2007; Shinozaki et al., 2009; Casuso et al., 2010; Milhiet et al., 2010; Sugimoto et al., 2010; Wickham et al., 2011). Thus, the application of this new microscopy is now expanding and will become a tool commonly used for biophysical studies in the near future.

\section{Acknowledgements}

The authors thank Daisuke Yamamoto, Hayato Yamashita, Mikihiro Shibata, Ryota Iino, Hiroyuki Noji, Kiyohiko Igarashi, Hideki Kandori and present and previous many students in Ando lab for collaborations or contributions to the works described in this chapter. Long-term financial support by NEDO, JST (CREST project), JSPS (Grant-in-Aid for Basic Research (S)), Knowledge Cluster Initiative, and the Mitsubishi Foundation is gratefully acknowledged.

\section{References}

Abrahams, J.P., Leslie, A.G.W., Lutter, R., and Walker, J.E. (1994). Structure at $2.8 \AA$ resolution of F1-ATPase from bovine heart mitochondri. Nature 370:621628.

Abuja, P.M., Pilz, I., Claeyssens, M., and Tomme, P. (1988a). Domain structure of cellobiohydrolase II as studied by small angle X-ray scattering: close resemblance to cellobiohydrolase I. Biochem. Biophys. Res. Commun. 156:180-185.

Abuja, P.M., Schmuck, M., Pilz, I., Tomme, P., Claeyssens, M., and Esterbauer, H. (1988b). Structural and functional domains of cellobiohydrolase I from trichoderma reesei. Eur. Biophys. J. 15:339-342.

Abuja, P.M., Pilz, I., Tomme, P., and Claeyssens, M. (1989). Structural changes in cellobiohydrolase I upon binding of a macromolecular ligand as evident by SAXS investigations. Biochem. Biophys. Res. Commun. 165:615-623.

Adachi, K., Oiwa, K., Nishizaka, T., Furuike, S., Noji, H., Itoh, H., Yoshida, M., and Kinosita, K. (2007). Coupling of rotation and catalysis in $\mathrm{F}_{1}$-ATPase revealed by single-molecule imaging and manipulation. Cell 130:309-321.

Aloise, P., Kagawa, Y., and Coleman, P.S. (1991). Comparative $\mathrm{Mg}^{2+}$-dependent sequential covalent binding stoichiometries of 3'-O-(4-benzoyl)benzoyl adenosine 5'-diphosphate of $\mathrm{MF}_{1}, \mathrm{TF}_{1}$, and the alpha 3 beta 3 core complex of $\mathrm{TF}_{1}$. The binding change motif is independent of the F1 gamma delta epsilon sub. J. Biol. Chem. 266:10368-10376. 
Ando, T. (2012) High-speed atomic force microscopy coming of age. Nanotechnology 23:062001 (27 pp).

Ando, T., Kodera, N., Maruyama, D., Takai, E., Saito, K., and Toda, A. (2002). A High-Speed Atomic Force Microscope for Studying Biological Macromolecules in Action. Jpn. J. Appl. Phys. 41:4851-4856.

Ando, T., Kodera, N., Takai, E., Maruyama, D., Saito, K., and Toda, A. (2001). A high-speed atomic force microscope for studying biological macromolecules in action. Proc. Nat. Acad. Sci. USA 98:12468-12472.

Ando, T., Kodera, N., Uchihashi, T., Miyagi, A., Nakakita, R., Namashita, H., and Matada, K. 2005. High-speed Atomic Force Microscopy for Capturing Dynamic Behavior of Protein Molecules at Work. e-J. Surf. Sci. Nanotech. 3:384-392.

Ando, T., Uchihashi, T., and Fukuma, T. (2008). High-speed atomic force microscopy for nano-visualization of dynamic biomolecular processes. Prog. Surf. Sci. $83: 337-437$.

Bezanilla, M., Drake, B., Nudler, E., Kashlev, M., Hansma, P.K., and Hansma, H.G. (1994). Motion and enzymatic degradation of DNA in the atomic force microscope. Biophys. J. 67:2454-2459.

Binnig, G. (1992). Force microscopy. Ultramicroscopy 42-44:7-15.

Binnig, G., Quate, C., Gerber, Ch. (1986). Phys. Rev. Lett. 56:930-933.

Boisset, C., Fraschini, C., Schulein, M., Henrissat, B., and Chanzy, H. (2000). Imaging the enzymatic digestion of bacterial cellulose ribbons reveals the endo character of the cellobiohydrolase Cel6A from humicola insolens and its mode of synergy with cellobiohydrolase Cel7A. Appl. Environ. Microbiol. 66:1444-1452.

Boraston, A.B., Bolam, D.N., Gilbert, H.J., and Davies, G.J. (2004). Carbohydrate-binding modules: fine-tuning polysaccharide recognition. Biochem. J. 382: 769-781.

Boyer, P.D. (1993). The binding change mechanism for ATP synthase--some probabilities and possibilities. Biochim. Biophys. Acta 1140:215-250.

Boyer, P.D. (1997). The ATP synthase--a splendid molecular machine. Annu. Rev. Biochem. 66:717-749.

Burgess, S., Walker, M., Wang, F., Sellers, J.R., White, H.D., Knight, P.J., and Trinick, J. (2002). The prepower stroke conformation of myosin V. J. Cell Biol. 159:983-991.

Capaldi, R.A. (1998). Unisite Catalysis without Rotation of the $\gamma-\varepsilon$ Domain in Escherichia coli F 1 -ATPase. Biochemistry 273:15940-15945. 
Casuso, I., Kodera, N., Le Grimellec, Ch., Ando, T., and Scheuring, S. (2009). High-resolution high-speed contact mode atomic force microscopy movies of purple membrane. Biophys $J$, 97:1354-1361.

Casuso, I., Sens, P., Rico, F., and Scheuring, S. (2010). Experimental evidence for membrane-mediated protein-protein interaction. Biophys. J. 99:L47-L49.

Chanzy, H., and Henrissat, B. (1985). Unidirectional degradation of Valonia cellulose microcrystals subjected to cellulase action. FEBS Lett. 184:285-288.

Crampton, N., Yokokawa, M., Dryden, D.T.F., Edwardson, J.M., Rao, D.N., Takeyasu, K., Yoshimura, S.H., and Henderson, R.M. (2007). Fast-scan atomic force microscopy reveals that the type III restriction enzyme EcoP15I is capable of DNA translocation and looping. Proc. Natl Acad. Sci. USA 104:12755-12760.

Davies, G., and Henrissat, B. (1995). Structures and mechanisms of glycosyl hydrolases. Structure 3:853-859.

Divne, C., Stahlberg, J., Reinikainen, T., Ruohonen, L., Pettersson, G., Knowles, J., Teeri, T., and Jones, T. (1994). The three-dimensional crystal structure of the catalytic core of cellobiohydrolase I from Trichoderma reesei. Science 265:524528.

Divne, C., Ståhlberg, J., Teeri, T.T., and Jones, T.A. (1998). High-resolution crystal structures reveal how a cellulose chain is bound in the $50 \mathrm{~A}$ long tunnel of cellobiohydrolase I from Trichoderma reesei. J. Mol. Biol. 275:309-325.

Drake, B., Prater, C., Weisenhorn, A., Gould, S., Albrecht, T., Quate, C., Cannell, D., Hansma, H., and Hansma, P. (1989). Imaging crystals, polymers, and processes in water with the atomic force microscope. Science 243:1586-1589.

Endo, M., and Sugiyama, H. (2009a). Three-dimensional DNA nanostructures constructed by folding of multiple rectangles. Nucleic Acids Symp. Ser. 53:81-82.

Endo, M., Hidaka, K., Kato, T., Namba, K., and Sugiyama, H. (2009b). DNA prism structures constructed by folding of multiple rectangular arms. J. Am. Chem. Soc. 131:15570-15571.

Endo, M., Hidaka, K., and Sugiyama, H. (2011). Direct AFM observation of an opening event of a DNA cuboid constructed via a prism structure. Org. Biomol. Chem. 9:2075-2077.

Endo, M., Katsuda, Y., Hidaka, K., and Sugiyama, H. (2010). Regulation of DNA methylation using different tensions of double strands constructed in a defined DNA nanostructure. J. Am. Chem. Soc. 132:1592-1597.

Endo, M., Sugita, T., Katsuda, Y., Hidaka, K., and Sugiyama, H. (2010). Programmed-Assembly System Using DNA Jigsaw Pieces. Chem. Eur. J. 16:53625368. 
Eriksson, T., Karlsson, J., and Tjerneld, F. (2002). A Model Explaining Declining Rate in Hydrolysis of Lignocellulose Substrates with Cellobiohydrolase I (Cel7A) and Endoglucanase I (Cel7B) of Trichoderma reesei. Appl. Biochem. Biotech. 101: 41-60.

Fantner, G.E., Barbero, R.J., Gray, D.S., and Belcher, A.M. (2010). Kinetics of antimicrobial peptide activity measured on individual bacterial cells using highspeed atomic force microscopy. Nat. Nanotechnol. 5:280-285.

Forgacs, E., Cartwright, S., Sakamoto, T., Sellers, J.R., Corrie, J.E.T., Webb, M.R., and White, H.D. (2008). Kinetics of ADP dissociation from the trail and lead heads of actomyosin V following the power stroke. J. Biol. Chem. 283:766-773.

Forkey, J.N., Quinlan, M.E., Shaw, M.A., Corrie, J.E.T., and Goldman, Y.E. (2003). Three-dimensional structural dynamics of myosin V by single-molecule fluorescence polarization. Nature 422:399-404.

Fukuma, T., Okazaki, Y., Kodera, N., Uchihashi, T., and Ando, T. (2008). High resonance frequency force microscope scanner using inertia balance support. Appl. Phys. Lett. 92:243119 (3 pp).

Furuike, S., Hossain, M.D., Maki, Y., Adachi, K., Suzuki, T., Kohori, A., Itoh, H., Yoshida, M., and Kinosita, K. (2008). Axle-less $\mathrm{F}_{1}$-ATPase rotates in the correct direction. Science 319:955-958.

Geeves, M.A., and Holmes, K.C. (1999). Structura mechanism of muscle contraction. Annu. Rev. Biochem. 68:687-728.

Gilmore, J. L., Suzuki, Y., Tamulaitis, G., Siksnys, V., Takeyasu, K., and Lyubchenko, Y. L. (2009). Single-molecule dynamics of the DNA-EcoRII protein complexes revealed with high-speed atomic force microscopy. Biochemistry 48: 10492-10498.

Giocondi, M.-C., Yamamoto, D., Lesniewska, E., Milhiet, P.-E., Ando, T., and Le Grimellec, C. (2010). Surface topography of membrane domains. Biochim. Biophys. Acta-Biomembranes, 1798:703-718.

Goldman, Y.E. (1987). Kinetics of the actomyosin ATPase in muscle fibers. Ann. Rev. Physiol. 49:637-654.

Guthold, M., Bezanilla, M., Erie, D.A., Jenkins, B., Hansma, H.G., and Bustamante, C. (1994). Following the assembly of RNA polymerase-DNA complexes in aqueous solutions with the scanning force microscope. Proc. Natl Acad. Sci. USA 91:12927-12931.

Häberle, W., Hörber, J.K.H., Ohnesorge, F., Smith, D.P.E., and Binnig, G. (1992). In situ investigations of single living cells infected by viruses. Ultramicroscopy $42-$ 44: 1161-1167. 
Hansma, H.G., Bezanilla, M., Zenhausern, F., Adrian, M., and Sinsheimer, R.L. (1993). Atomic force microscopy of DNA in aqueous solutions. Nucleic Acids Res. 21:505-512.

Henrissat, B. (1991). A classification of glycosyl hydrolases based on amino acid sequence similarities. Biochem. J. 280:309-316.

Henrissat, B., and Bairoch, A. (1993). New families in the classification of glycosyl hydrolases based on amino acid sequence similarities. Biochem. J. 280:781788.

Henrissat, B., Driguez, H., Viet, C., and Schülein, M. (1985). Synergism of Cellulases from Trichoderma reesei in the Degradation of Cellulose. Nat. Biotechnol. 3: $722-726$.

Henrissat, B., Teeri, T.T., and Warren, R.A. (1998). A scheme for designating enzymes that hydrolyse the polysaccharides in the cell walls of plants. FEBS Lett. 425:352-354.

Hon, D.N.S. (1994). Cellulose: a random walk along its historical path. Cellulose $1: 1-25$.

Hossain, M.D., Furuike, S., Maki, Y., Adachi, K., Ali, M.Y., Huq, M., Itoh, H., Yoshida, M., and Kinosita, K. (2006). The rotor tip inside a bearing of a thermophilic F1-ATPase is dispensable for torque generation. Biophys. J. 90:4195-4203.

Hossain, M.D., Furuike, S., Maki, Y., Adachi, K., Suzuki, T., Kohori, A., Itoh, H., Yoshida, M., and Kinosita, K. (2008). Neither helix in the coiled coil region of the axle of F1-ATPase plays a significant role in torque production. Biophys. J. 95: $4837-4844$.

Hua, W., Chung, J., and Gelles, J. (2002). Distinguishing inchworm and handover-hand processive kinesin movement by neck rotation measurements. Science 295:844-848.

Huxley, H.E. (1969). The Mechanism of Muscular Contraction. Science 164: 1356-1366.

Igarashi, K., Koivula, A., Wada, M., Kimura, S., Penttilä, M., and Samejima, M. (2009). High speed atomic force microscopy visualizes processive movement of Trichoderma reesei cellobiohydrolase I on crystalline cellulose. J. Biol. Chem. 284 36186-36190.

Igarashi, K., Uchihashi, T., Koivula, A., Wada, M., Kimura, S., Okamoto, T., Penttila, M., Ando, T., and Samejima, M. (2011). Traffic Jams Reduce Hydrolytic Efficiency of Cellulase on Cellulose Surface. Science 333:1279-1282. 
Igarashi, K., Wada, M., and Samejima, M. (2007). Activation of crystalline cellulose to cellulose III(I) results in efficient hydrolysis by cellobiohydrolase. FEBS J. 274:1785-1792.

Iko, Y., Tabata, K.V., Sakakihara, S., Nakashima, T., and Noji, H. (2009). Acceleration of the ATP-binding rate of F1-ATPase by forcible forward rotation. FEBS Lett. 583:3187-3191.

Imai, T., Boisset, C., Samejima, M., Igarashi, K., and Sugiyama, J. (1998). Unidirectional processive action of cellobiohydrolase Cel7A on Valonia cellulose microcrystals. FEBS Lett. 432:113-116.

Inoue, S., Uchihashi, T., Yamamoto, D., and Ando, T. (2011). Direct observation of surfactant aggregate behavior on a mica surface using high-speed atomic force microscopy. Chem. Commun. 47:4974-4976.

Itoh, H., Takahashi, A., Adachi, K., Noji, H., Yasuda, R., Yoshida, M., and Kinosita, K. (2004). Mechanically driven ATP synthesis by $\mathrm{F}_{1}$-ATPase. J. Jap. Biochem. Soc. 427:42-45.

Johansson, G., Stahlberg, J., Lindeberg, G., Engstrom, A., and Pettersson, G. (1989). Isolated fungal cellulose terminal domains and a synthetic minimum analogue bind to cellulose. FEBS Lett. 243:389-393.

Joo, C., Balci, H., Ishitsuka, Y., Buranachai, C., and Ha, T. (2008). Advances in single-molecule fluorescence methods for molecular biology. Ann. Rev. Biochem. $77: 51-76$

Kaibara, C., Matsui, T., Hisabori, T., and Yoshida, M. (1996). Structural asymmetry of $\mathrm{F}_{1}$-ATPase caused by the gamma subunit generates a high affinity nucleotide binding site. J. Biol. Chem. 271:2433-2438.

Kasas, S., Thomson, N.H., Smith, B.L., Hansma, H.G., Zhu, X., Guthold, M., Bustamante, C., Kool, E.T., Kashlev, M., and Hansma, P.K. (1997). Escherichia coli RNA polymerase activity observed using atomic force microscopy. Biochemistry 36:461-468.

Kitazawa, M., Shiotani, K., and Toda, A. (2003). Batch Fabrication of Sharpened Silicon Nitride Tips. Jpn. J. Appl. Phys. 42:4844-4847.

Kodera, N., Sakashita, M., and Ando, T. (2006). Dynamic proportional-integraldifferential controller for high-speed atomic force microscopy. Rev. Sci. Instrum. 77:083704 (7 pp).

Kodera, N., Yamamoto, D., Ishikawa, R., and Ando, T. (2010). Video imaging of walking myosin V by high-speed atomic force microscopy. Nature 468:72-76. 
Kodera, N., Yamashita, H., and Ando, T. (2005). Active damping of the scanner for high-speed atomic force microscopy. Rev. Sci. Instrum. 76:053708 (5 pp).

Kokavecz, J., Tóth, Z., Horváth, Z.L., Heszler, P., and Mechler, Á. (2006). Novel amplitude and frequency demodulation algorithm for a virtual dynamic atomic force microscope. Nanotechnology 17:S173-S177.

De La Cruz, E.M., Wells, A.L., Rosenfeld, S.S., Ostap, E.M., and Sweeney, H.L. (1999). The kinetic mechanism of myosin V. Proc. Natl Acad. Sci. USA 96: 13726-13731.

Lin, H., Clegg, D.O., and Lal, R. (1999). Imaging real-time proteolysis of single collagen I molecules with an atomic force microscope. Biochemistry 38:99569963.

Linder, M. (1997). The roles and function of cellulose-binding domains. J. Biotech. $57: 15-28$

Lindsay, S.M., Nagahara, L.A., Thundat, T., Knipping, U., Rill, R.L., Drake, B., Prater, C.B., Weisenhorn, A.L., Gould, S.A., and Hansma, P.K. (1989). STM and AFM images of nucleosome DNA under water. J. Biomol. Struct. Dynam. 7:27987.

Matsui, T., and Yoshida, M. (1995). Expression of the wild-type and the Cys-/Trpless alpha 3 beta 3 gamma complex of thermophilic $F_{1}$-ATPase in Escherichia coli. Biochim. Biophys. 1231:139-146.

Mehta, A.D., Rock, R.S., Rief, M., Spudich, J.A., Mooseker, M.S., and Cheney, R.E. (1999). Myosin-V is a processive actin-based motor. Nature 400:590-593.

Menz, R.I., Walker, J.E., and Leslie, A.G. (2001). Structure of bovine mitochondrial F(1)-ATPase with nucleotide bound to all three catalytic sites: implications for the mechanism of rotary catalysis. Cell 106:331-341.

Milhiet, P.-E., Yamamoto, D., Berthoumieu, O., Dosset, P., Le Grimellec, C., Verdier, J.-M., Marchal, S., and Ando, T. (2010). Deciphering the Structure, Growth and Assembly of Amyloid-Like Fibrils Using High-Speed Atomic Force Microscopy. PLoS One 5:e13240 (8 pp).

Miyagi, A., Tsunaka, Y., Uchihashi, T., Mayanagi, K., Hirose, S., Morikawa, K., and Ando, T. (2008). Visualization of intrinsically disordered regions of proteins by high-speed atomic force microscopy. ChemPhysChem 9:1859-1866.

Müller, D.J., Büldt, G., and Engel, A. (1995). Force-induced conformational change of bacteriorhodopsin. J. Mol. Biol. 249:239-243.

Müller, D.J., and Engel, A. (1999). Voltage and pH-induced channel closure of porin OmpF visualized by atomic force microscopy. J. Mol. Biol. 285:1347-1351. 
Nakamoto, R.K., Ketchum, C.J., and Al-Shawi, M.K. (1999). Rotational coupling in the $\mathrm{F}_{0} \mathrm{~F}_{1}$ ATP synthase. Ann. Rev. Biophys. and Biomol. Struct. 28:205-234.

Nidetzky, B., Steiner, W., Hayn, M., and Claeyssens, M. (1994). Cellulose hydrolysis by the cellulases from Trichoderma reesei: a new model for synergistic interaction. Biochem. J. 298:705-710.

Nishiyama, Y., Sugiyama, J., Chanzy, H., and Langan, P. (2003). Crystal structure and hydrogen bonding system in cellulose I(alpha) from synchrotron X-ray and neutron fiber diffraction. J. Am. Chem. Soc. 125:14300-14306.

Noji, H., Yasuda, R., Yoshida, M., and Kinosita, K. (1997). Direct observation of the rotation of F1-ATPase. Nature 386:299-302.

Oberleithner, H., Schillers, H., Wilhelmi, M., Butzke, D., and Danker, T. (2000). Nuclear pores collapse in response to $\mathrm{CO} 2$ imaged with atomic force microscopy. Pflug. Arch. Eur. J. Phy. 439:251-255.

Oguchi, Y., Mikhailenko, S.V., Ohki, T., Olivares, A.O., De La Cruz, E.M., and Ishiwata, S. (2008). Load-dependent ADP binding to myosins V and VI: implications for subunit coordination and function. Proc. Natl. Acad. Sci. USA 105: 7714-7719.

Ohnesorge, F., Heckl, W.M., Häberle, W., Pum, D., Sara, M., Schindler, H., Schilcher, K., Kiener, A., Smith, D.P., and Sleytr, U.B. (1992). Scanning force microscopy studies of the S-layers from Bacillus coagulans E38-66, Bacillus sphaericus CCM2177 and of an antibody binding process. Ultramicroscopy 42 $44: 1236-1242$.

Okada, T., Tanaka, H., Iwane, A.H., Kitamura, K., Ikebe, M., and Yanagida, T. (2007). The diffusive search mechanism of processive myosin class-V motor involves directional steps along actin subunits. Biochem. Biophysi. Res. Commun. 354:379-384.

Oke, O.A., Burgess, S.A., Forgacs, E., Knight, P.J., Sakamoto, T., Sellers, J.R., White, H., and Trinick, J. (2010). Influence of lever structure on myosin 5a walking. Proc. Natl. Acad. Sci. USA 107:2509-2514.

Peterman, E.J.G., Sosa, H., and Moerner, W.E. (2004). Single-molecule fluorescence spectroscopy and microscopy of biomolecular motors. Ann. Rev. Phys. Chem. 55:79-96.

Purcell, T.J., Sweeney, H.L., and Spudich, J.A. (2005). A force-dependent state controls the coordination of processive myosin V. Proc. Natl. Acad. Sci. USA 102: $13873-13878$. 
Putman, C.A.J., Van Der Werf, K.O., De Grooth, B.G., Van Hulst, N.F., and Greve, J. (1994). Tapping mode atomic force microscopy in liquid. Appl. Phys. Lett. 64:2454-2456.

Rajendran, A., Endo, M., Katsuda, Y., Hidaka, K., and Sugiyama, H. (2011). Programmed two-dimensional self-assembly of multiple DNA origami jigsaw pieces. ACS Nano 5:665-671.

Reverbel-Leroy, C., Pages, S., Belaich, A., Belaich, J.P., and Tardif, C. (1997). The processive endocellulase CelF, a major component of the Clostridium cellulolyticum cellulosome: purification and characterization of the recombinant form. $J$. Bacteriol. 179:46-52.

Rondelez, Y., Tresset, G., Nakashima, T., Kato-Yamada, Y., Fujita, H., Takeuchi, S., and Noji, H. (2005). Highly coupled ATP synthesis by $F_{1}$-ATPase single molecules. Nature 433:773-777.

Rosenfeld, S.S., and Sweeney, H.L. (2004). A model of myosin V processivity. $J$. Biol. Chem. 279:40100-40111.

Rouvinen, J., Bergfors, T., Teeri, T., Knowles, J.K., and Jones, T.A. (1990). Three-dimensional structure of cellobiohydrolase II from Trichoderma reesei. Science 249:380-386.

Roy, R., Hohng, S., and Ha, T. (2008). A practical guide to single-molecule FRET. Nat. Methods 5:507-516.

Ryu, D.D.Y., and Mandels, M. (1980). Cellulases: Biosynthesis and applications. Enzyme Microb. Tech. 2:91-102.

Sakamoto, T., Amitani, I., Yokota, E., and Ando, T. (2000). Direct observation of processive movement by individual myosin V molecules. Biochem. Biophys. Res. Commun. 272:586-590.

Sakamoto, T., Webb, M.R., Forgacs, E., White, H.D., and Sellers, J.R. (2008). Direct observation of the mechanochemical coupling in myosin Va during processive movement. Nature 455:128-132.

Sannohe, Y., Endo, M., Katsuda, Y., Hidaka, K., and Sugiyama, H. (2010). Visualization of dynamic conformational switching of the G-quadruplex in a DNA nanostructure. J. Am. Chem. Soc. 132:16311-16313.

Schabert, F.A., and Engel, A. (1994). Reproducible acquisition of Escherichia coli porin surface topographs by atomic force microscopy. Biophys. J. 67:2394-2403.

Schäffer, T.E., Cleveland, J.P., Ohnesorge, F., Walters, D.A., and Hansma, P.K. (1996). Studies of vibrating atomic force microscope cantilevers in liquid. J. Appl. Phys. 80:3622-3627. 
Sellers, J.R., and Weisman, L.S. (2008). 289-324 in Myosins: A Superfamily of Molecular Motors, Proteins and Cell Regulation (ed. Coluccio, L.M.). Springer, Netherland.

Shao, Z., and Yang, J. (1995). Progress in high resolution atomic force microscopy in biology. Q. Rev. Bio. 28:195-251.

Shibata, M., Uchihashi, T., Yamashita, H., Kandori, H., and Ando, T. (2011). Structural changes in bacteriorhodopsin in response to alternate illumination observed by high-speed atomic force microscopy. Angew. Chem. Int. Ed. 50:44104413.

Shibata, M., Yamashita, H., Uchihashi, T., Kandori, H., and Ando, T. (2010). High-speed atomic force microscopy shows dynamic molecular processes in photoactivated bacteriorhodopsin. Nat. Nanotech. 5:208-212.

Shinozaki, Y., Sumitomo, K., Tsuda, M., Koizumi, S., Inoue, K., and Torimitsu, K. (2009). Direct Observation of ATP-Induced Conformational Changes in Single P2X4 Receptors. PLoS Biol. 7:e1000103 (12 pp).

Shirakihara, Y., Leslie, a G., Abrahams, J.P., Walker, J.E., Ueda, T., Sekimoto, Y., Kambara, M., Saika, K., Kagawa, Y., and Yoshida, M. (1997). The crystal structure of the nucleotide-free alpha 3 beta 3 subcomplex of $\mathrm{F}_{1}$-ATPase from the thermophilic Bacillus $\mathrm{PS}_{3}$ is a symmetric trimer. Structure 5:825-836.

Ståhlberg, J., Johansson, G., and Pettersson, G. (1991). A New Model For Enzymatic Hydrolysis of Cellulose Based on the Two-Domain Structure of Cellobiohydrolase I. Bio/Technology 9:286-290.

Sugimoto, S., Yamanaka, K., Nishikori, S., Miyagi, A., Ando, T., and Ogura, T. (2010). AAA+ chaperone ClpX regulates dynamics of prokaryotic cytoskeletal protein FtsZ. J. Biol. Chem. 285:6648-6657.

Suzuki, Y., Higuchi, Y., Hizume, K., Yokokawa, M., Yoshimura, S. H., Yoshikawa, K., and Takeyasu, K. (2010). Molecular dynamics of DNA and nucleosomes in solution studied by fast-scanning atomic force microscopy. Ultramicroscopy, 110:682-688.

Teeri, T.T. (1997). Crystalline cellulose degradation: new insight into the function of cellobiohydrolases. Trends Biotech. 15:160-167.

Teeri, T.T., Koivula, A., Linder, M., Wohlfahrt, G., Divne, C., and Jones, T.A. (1998). Trichoderma reesei cellobiohydrolases: why so efficient on crystalline cellulose? Biochem. Soc. Trans. 26:173-178.

Todd, R.D., Griesenbeck, T.A., and Douglas, M.G. (1980). The yeast mitochondrial adenosine triphosphatase complex. Subunit stoichiometry and physical characterization. J. Biol. Chem. 255:5461-5467. 
Uchihashi, T., Iino, R., Ando, T., and Noji, H. (2011). High-Speed Atomic Force Microscopy Reveals Rotary Catalysis of Rotorless F $F_{1}$-ATPase. Science 333:755758.

Veigel, C., Schmitz, S., Wang, F., and Sellers, J.R. (2005). Load-dependent kinetics of myosin-V can explain its high processivity. Nat.e Cell Biol. 7:861-869.

Wada, M., Chanzy, H., Nishiyama, Y., and Langan, P. (2004). Cellulose III I Crystal Structure and Hydrogen Bonding by Synchrotron X-ray and Neutron Fiber Diffraction. Macromolecules 37:8548-8555.

Walker, J.E., Fearnley, I.M., Gay, N.J., Gibson, B.W., Northrop, F.D., Powell, S.J., Runswick, M.J., Saraste, M., and Tybulewicz, V.L. (1985). Primary structure and subunit stoichiometry of F1-ATPase from bovine mitochondria. J. Mol. Biol. 184: $677-701$.

Walker, M.L., Burgess, S.A., Sellers, J.R., Wang, F., Hammer, J.A., Trinick, J., and Knight, P.J. (2000). Two-headed binding of a processive myosin to F-actin. Nature 405:804-807.

Walz, T., Tittmann, P., Fuchs, K.H., Müller, D.J., Smith, B.L., Agre, P., Gross, H., and Engel, A. (1996). Surface topographies at subnanometer-resolution reveal asymmetry and sidedness of aquaporin-1. J. Mol. Biol. 264:907-918.

Wang, H., and Oster, G. (1998). Energy transduction in the F1 motor of ATP synthase. Nature 396:279-282.

Watanabe, R., Iino, R., and Noji, H. (2010). Phosphate release in F1-ATPase catalytic cycle follows ADP release. Nat. Chem. Biol. 6:814-820.

Weisenhorn, A.L., Hansma, P.K., Albrecht, T.R., and Quate, C.F. (1989). Forces in atomic force microscopy in air and water. Appl. Phys. Lett. 54:2651 (3 pp).

Wendel, M., Lorenz, H., and Kotthaus, J.P. (1995). Sharpened electron beam deposited tips for high resolution atomic force microscope lithography and imaging. Appl. Phys. Lett. 67:3732 (3 pp).

Wickham, S.F.J., Endo, M., Katsuda, Y., Hidaka, K., Bath, J., Sugiyama, H., andTurberfield, A.J. (2011). Direct observation of stepwise movement of a synthetic molecular transporter. Nat. Nanotechnol. 6:166-169.

Wood, T.M., and McCrae, S.I. (1978). The cellulase of Trichoderma koningii. Purification and properties of some endoglucanase components with special reference to their action on cellulose when acting alone and in synergism with the cellobiohydrolase. Biochem. J. 171:61-72. 
Yamamoto, D., Nagura, N., Omote, S., Taniguchi, M., and Ando, T. (2009). Streptavidin 2D Crystal Substrates for Visualizing Biomolecular Processes by Atomic Force Microscopy. Biophys. J. 97:2358-2367.

Yamamoto, D., Uchihashi, T., Kodera, N., and Ando, T. (2008). Anisotropic diffusion of point defects in a two-dimensional crystal of streptavidin observed by high-speed atomic force microscopy. Nanotechnology 19:384009 (9 pp).

Yamamoto, D., Uchihashi, T., Kodera, N., Yamashita, H., Nishikori, S., Ogura, T., Shibata, M., and Ando, T. (2010). High-speed atomic force microscopy techniques for observing dynamic biomolecular processes. Methods Enzymol. 475:541-564.

Yamashita, H., Voïtchovsky, K., Uchihashi, T., Contera, S.A., Ryan, J.F., and Ando, T. (2009). Dynamics of bacteriorhodopsin 2D crystal observed by high-speed atomic force microscopy. J. Struct. Biol. 167:153-158.

Yanagida, T., and Ishii, Y. (Eds.) (2008). Single Molecule Dynamics in Life Science. Wiley-VCH Verlag GmbH \& Co. KGaA, Weinheim, Germany.

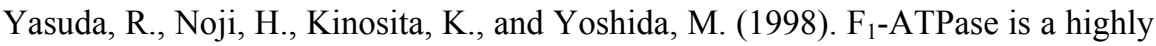
efficient molecular motor that rotates with discrete 120 degree steps. Cell 93:1117-1124.

Yildiz, A., Forkey, J.N., McKinney, S.A., Ha, T., Goldman, Y.E., and Selvin, P.R. (2003). Myosin V Walks Hand-Over-Hand: Single Fluorophore Imaging with 1.5nm Localization. Science 300:2061-2065.

Yokokawa, M., Carnally, S. M., Henderson, R. M., Takeyasu, K., and Edwardson, J. M. (2010). Acid-sensing ion channel (ASIC) 1a undergoes a height transition in response to acidification. FEBS Lett. 584:3107-3110.

Yokokawa, M., Wada, C., Ando, T., Sakai, N., Yagi, A., Yoshimura, S.H., and Takeyasu, K. (2006a). Fast-scanning atomic force microscopy reveals the ATP/ADP-dependent conformational changes of GroEL. EMBO J. 25:4567-4576.

Yokokawa, M., Yoshimura, S. H., Naito, Y., Ando, T., Yagi, A., Sakai, N., and Takeyasu, K. (2006b). Fast-scanning atomic force microscopy reveals the molecular mechanism of DNA cleavage by ApaI endonuclease. IEE Proc. Nanobiotechnol. 153:60-66.

Yoshida, M., and Allison, W.S. (1990). The ATPase activity of the alpha 3 beta 3 complex of the $\mathrm{F}_{1}$-ATPase of the thermophilic bacterium $\mathrm{PS}_{3}$ is inactivated on modification of tyrosine 307 in a single beta subunit by 7-chloro-4nitrobenzofurazan. J. Biol. Chem. 265:2483-2487.

Zhong, Q., Inniss, D., Kjoller, K., and Elings, V.B. (1993). Fractured polymer/silica fiber surface studied by tapping mode atomic force. Surf. Sci. Lett. 290:L688-L692. 


\section{Figure Captions}

Fig. 1. Schematic of HS-AFM system.

Fig. 2. (a) Schematic models and AFM images of M5 (upper) and M5-HMM (lower). (b) Schematic showing assay system for HS-AFM imaging of walking M5-HMM molecules.

Fig. 3. (a) Successive AFM images showing unidirectional processive movement of M5-HMM observed in $1 \mu \mathrm{M}$ ATP (upper panels; scale bar, $30 \mathrm{~nm}$ ) and schematic showing two-headed bound M5-HMM (bottom). (b) Successive AFM images (right panel) showing hand-over-hand movement of M5-HMM in $1 \mu \mathrm{M}$ ATP (scale bar, $50 \mathrm{~nm}$ ) and schematic explaining the AFM images (left panel). The swinging lever is highlighted with the thin white lines (right panel). The vertical dashed lines in (a) and (b) show the centers of mass of the motor domains, and the plus signs indicate the plus ends of actin. All AFM images were taken at $7 \mathrm{fps}$.

Fig. 4. Other dynamic events of M5 HMM observed by HS-AFM. (a) Unfolding of coiled-coil tail of two-headed bound M5-HMM in $50 \mu \mathrm{M}$ ADP. Top image, before unfolding; bottom image, after unfolding. (b) Successive AFM images showing foot stomp at leading head observed in $1 \mu \mathrm{M}$ ATP. The events of leading head detachment from actin are indicated with the arrow heads. Imaging rate, $7 \mathrm{fps}$. (c) AFM image showing sharply bent leading head of two-headed bound M5-HMM in the nucleotide free condition. The marks " + " indicate the plus ends of actin filaments.

Fig. 5. Crystal structure of nucleotides-bound $F_{1}-A T P a s e$ (PDB code: 1BMF). (a) Top view. (b) Side view. (c) Side view in which the $\alpha$ subunit on the nearest face is removed. 
Fig. 6. (a) Wide-area AFM image of $\alpha_{3} \beta_{3}$ subcomplex without nucleotide. (b) and (c) are averaged experimental and simulated AFM images of C-terminal side of the $\alpha_{3} \beta_{3}$ subcomplex without nucleotide, respectively. (d) and (e) are averaged experimental and simulated AFM images of $N$-terminal side of the $\alpha_{3} \beta_{3}$ subcomplex without nucleotide. (f) Averaged AFM image of C-terminal side of the $\alpha_{3} \beta_{3}$ subcomplex in $1 \mathrm{mM}$ AMPPNP. (g) Atomic structure of $\alpha_{3} \beta_{3}$ subcomplex with bound nucleotides. This structure is obtained by removing $\gamma$ from a crystal structure of $F_{1}$. (h) Simulated AFM image constructed from the crystal structure shown in (g).

Fig. 7. (a) Successive AFM images showing conformational change in $\alpha_{3} \beta_{3}$ subcomplex in $2 \mu \mathrm{M}$ ATP. The highest pixel in each image is indicated by the red circle. Frame rate, 12.5 fps. (b) Tight correlation between two types of conformational changes in $\beta$ observed in ATP; conformations with different-height protrusions ("H," high; "L," low) and outwardly extended (E) and inwardly retracted $(\mathrm{R})$ conformations of the distal region. The higher protrusion is mostly accompanied by the E-conformation, whereas the lower protrusion is mostly accompanied by the R-conformation. (d) Time evolution of cumulated angle of highest pixel. The inset shows a trajectory, superimposed on an AFM image, of the highest pixels corresponding to the high protrusions of $\beta$ 's. The center of rotation is defined by the averaged $\mathrm{x}$ - and y-positions of the highest pixels, and the cumulated angles are calculated relative to the first frame. (d) and (e) Cessation of rotary propagation of conformational states upon loss of a single subunit. (d) AFM images before (left) and after (right) loss of $\beta_{1}$. (e) Cumulated angles of open $\beta$ measured using the highest pixel position in each frame. ATP concentration, 2 $\mu \mathrm{M}$; frame rate, 12.5 fps. $\beta_{1}$ is lost at $16.2 \mathrm{~s}$.

Fig. 8. Successive AFM images showing processive and unidirectional movement of $\operatorname{TrCel7A}$ on crystalline cellulose $\mathrm{I}_{\alpha}(\mathrm{a}, \mathrm{b})$. Frame rate, 1.1 fps. (a) The enzyme molecules move from the right to left on the crystal. (b) The movement of one molecule is halted and then following molecules are blocked at a position indicated by arrows. (c) Time course of displacement for individual $\operatorname{Tr} \mathrm{Cel} 7 \mathrm{~A}$ molecules. The different symbols indicate different molecules. (d) Velocity distribution of li- 
nearly moving $\operatorname{Tr}$ Cel7A molecules on crystalline cellulose $\mathrm{I}_{\alpha}$. The histogram was fitted by the combination (blue line) of two Gaussian distribution curves with mean \pm SD values of $-0.32 \pm 3.4$ (red) and $7.1 \pm 3.9$ (green).

Fig. 9. (a) Successive AFM images of $\operatorname{Tr}$ Cel7A molecules on crystalline cellulose IIII. Frame rate, 3.3 fps. (b) Fibrillation of crystalline cellulose III I $_{\mathrm{I}}$ after congestion of molecules. Frame rate, 3.3 fps. Schematics of sections of crystalline cellulose $\mathrm{I}_{\alpha}$ (c) and cellulose $\mathrm{III}_{\mathrm{I}}(\mathrm{d})$.

Fig. 10. (a) Synergy between $\operatorname{Tr}$ Cel6A and $\operatorname{Tr}$ Cel7A in cellobiose production from cellulose $\mathrm{III}_{\mathrm{I}}$. The green and red plots show the rates of cellobiose production by $\operatorname{Tr} \mathrm{Cel6 \textrm {A }}$ and $\operatorname{Tr} \mathrm{Cel} 7 \mathrm{~A}$, respectively, and the blue plot shows the synergy between the two enzymes. The dotted line indicates the simple sum of cellobiose production calculated from the green and red plots. (b) Successive AFM images after injection of $\operatorname{Tr}$ Cel6A to cellulose $\mathrm{III}_{\mathrm{I}}$ at $0 \mathrm{~s}$. The cellulose was not degraded even at 8 min. (c) Successive AFM images after $\operatorname{Tr}$ Cel7A was additionally added at $0 \mathrm{~s}$ (at $8.4 \mathrm{~min}$ after the initial addition of $\operatorname{Tr}$ Cel6A). The cellulose was rapidly degraded and almost disappeared at $\sim 4 \mathrm{~min}$. Frame rate, $3.3 \mathrm{fps}$ for (b) and (c) 
Table 1 Summary of published high-speed AFM imaging studies

\begin{tabular}{|c|c|c|}
\hline Subjects & Targets & References \\
\hline \multirow[t]{8}{*}{$\begin{array}{l}\text { Structure Dynamics } \\
\text { of Proteins }\end{array}$} & Myosin V & $\begin{array}{l}\text { Ando et al., 2001, 2002; Kodera } \\
\text { et al., } 2010\end{array}$ \\
\hline & Dynein $\mathrm{C}$ & Ando et al., 2005 \\
\hline & GroEL & Yokokawa et al., 2006a \\
\hline & $\begin{array}{l}\text { Intrinsically disordered } \\
\text { protein }\end{array}$ & Miyagi et al., 2008 \\
\hline & $\mathrm{P} 2 \mathrm{X}_{4}$ receptor & Shinozaki et al., 2009 \\
\hline & Bacteriorhodopsin & Shibata et al., 2010, 2011 \\
\hline & $\begin{array}{l}\text { Acid-sensing ion chan- } \\
\text { nel }\end{array}$ & Yokokawa et al., 2010 \\
\hline & $\mathrm{F}_{1}$-ATPase & Uchihashi et al., 2011 \\
\hline \multirow{6}{*}{$\begin{array}{l}\text { Dynamic Processes } \\
\text { of Proteins }\end{array}$} & Actin gliding & Ando et al. 2005 \\
\hline & GroEL-ES & $\begin{array}{l}\text { Ando et al. 2005; Yamamoto et } \\
\text { al., } 2009\end{array}$ \\
\hline & Cellulase on Cellulose & Igarashi et al., 2009, 2010 \\
\hline & ClpX-FtzZ & Sugimoto et al., 2010 \\
\hline & Amyloid-like fibrils & Milhiet et al., 2010 \\
\hline & C-ring of $\mathrm{F}_{\mathrm{o}}$ & Casuso et al., 2010 \\
\hline \multirow{5}{*}{$\begin{array}{l}\text { Protein-DNA Inte- } \\
\text { ractions }\end{array}$} & Apal endnuclease-DNA & Yokokawa et al., 2006b \\
\hline & $\begin{array}{l}\text { Type III restriction en- } \\
\text { zyme-DNA }\end{array}$ & Crampton et al., 2007 \\
\hline & $\begin{array}{l}\text { EcoRII restriction en- } \\
\text { zyme-DNA }\end{array}$ & Gilmore et al., 2009 \\
\hline & Histone-nucleosome & Suzuki et al., 2010 \\
\hline & $\begin{array}{l}\text { Synthetic molecular } \\
\text { transporter-DNA }\end{array}$ & Wickham et al., 2011 \\
\hline \multirow{2}{*}{$\begin{array}{l}\text { Dynamics of 2D - } \\
\text { Protein Crystals }\end{array}$} & Streptavidin & Yamamoto et al., 2008 \\
\hline & Bacteriorhodopsin & $\begin{array}{l}\text { Yamashita et al., 2009, Casuso } \\
\text { et al, } 2009\end{array}$ \\
\hline
\end{tabular}




\begin{tabular}{lll}
\hline Dynamics of DNA & $\begin{array}{l}\text { 3D hollow structure of } \\
\text { DNA origami }\end{array}$ & Endo et al., 2009a, 2009b \\
& $\begin{array}{l}\text { DNA origami jigsaw } \\
\text { pieces }\end{array}$ & $\begin{array}{l}\text { Endo et al., 2010a; Rajendran et } \\
\text { al., 2011 }\end{array}$ \\
& $\begin{array}{l}\text { DNA methylation } \\
\text { G-guadruplex in DNA } \\
\text { nanoscafold }\end{array}$ & $\begin{array}{l}\text { Endo et al., 2010b; Sannohe et } \\
\text { al. 2010, }\end{array}$ \\
& DNA cuboid & Endo et al., 2011 \\
\hline Others & $\begin{array}{l}\text { Process of cell death by } \\
\text { antimicrobial peptide }\end{array}$ & Fantner et al. 2010 \\
& $\begin{array}{l}\text { Lipid bilayer formaition } \\
\text { Morphological trans- } \\
\text { formation of detergent } \\
\text { micelles }\end{array}$ & Giocondi et al. 2010 \\
\hline
\end{tabular}




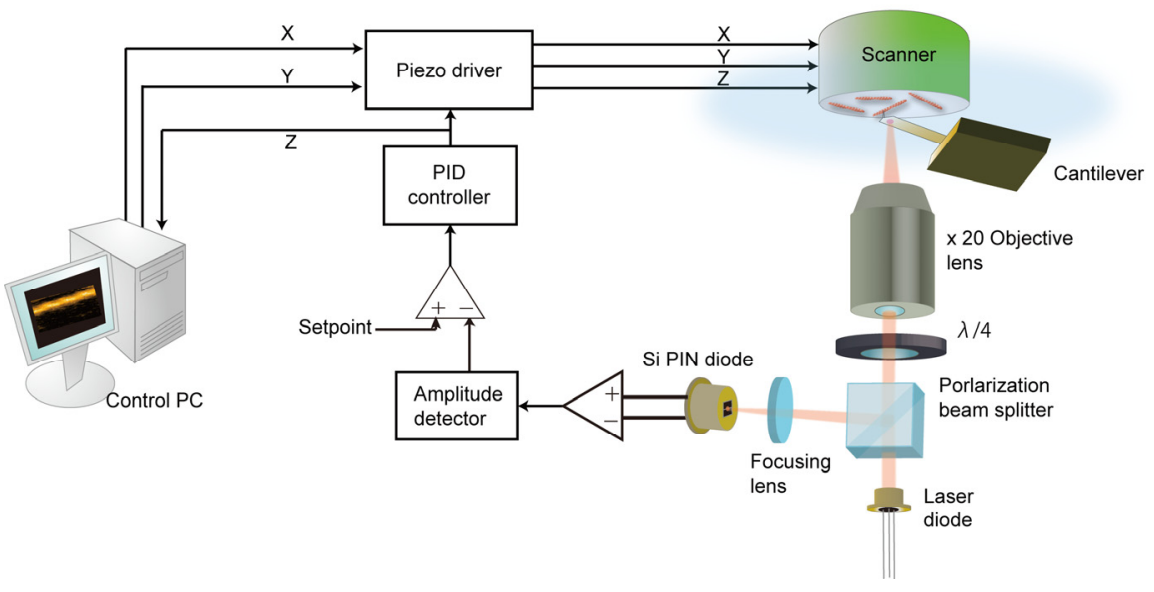

Fig. 1 
(a) globular tail domain

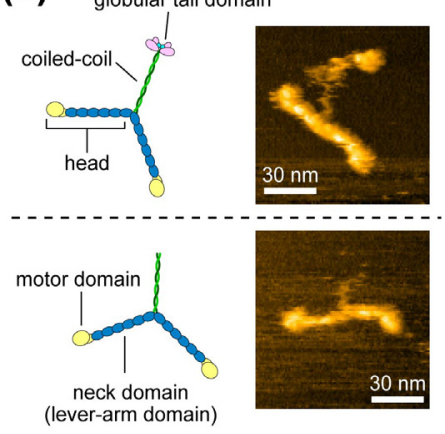

(b)

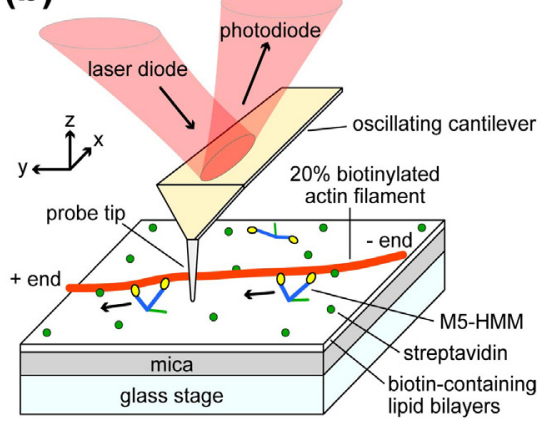

Fig. 2 (a)
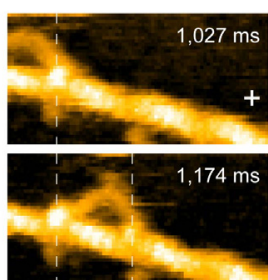

$2,201 \mathrm{~ms}$

$2,201 \mathrm{~ms}$
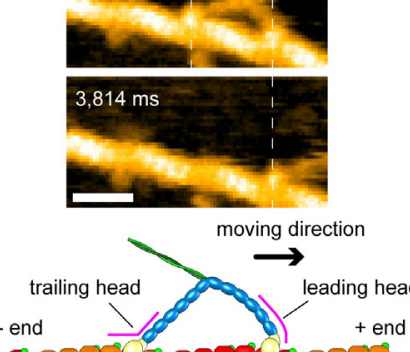

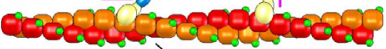

actin filament (b)

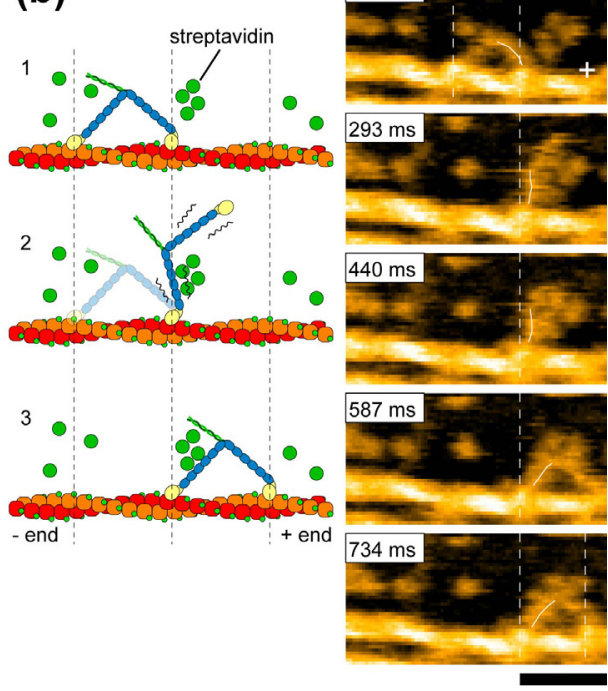

Fig. 3 


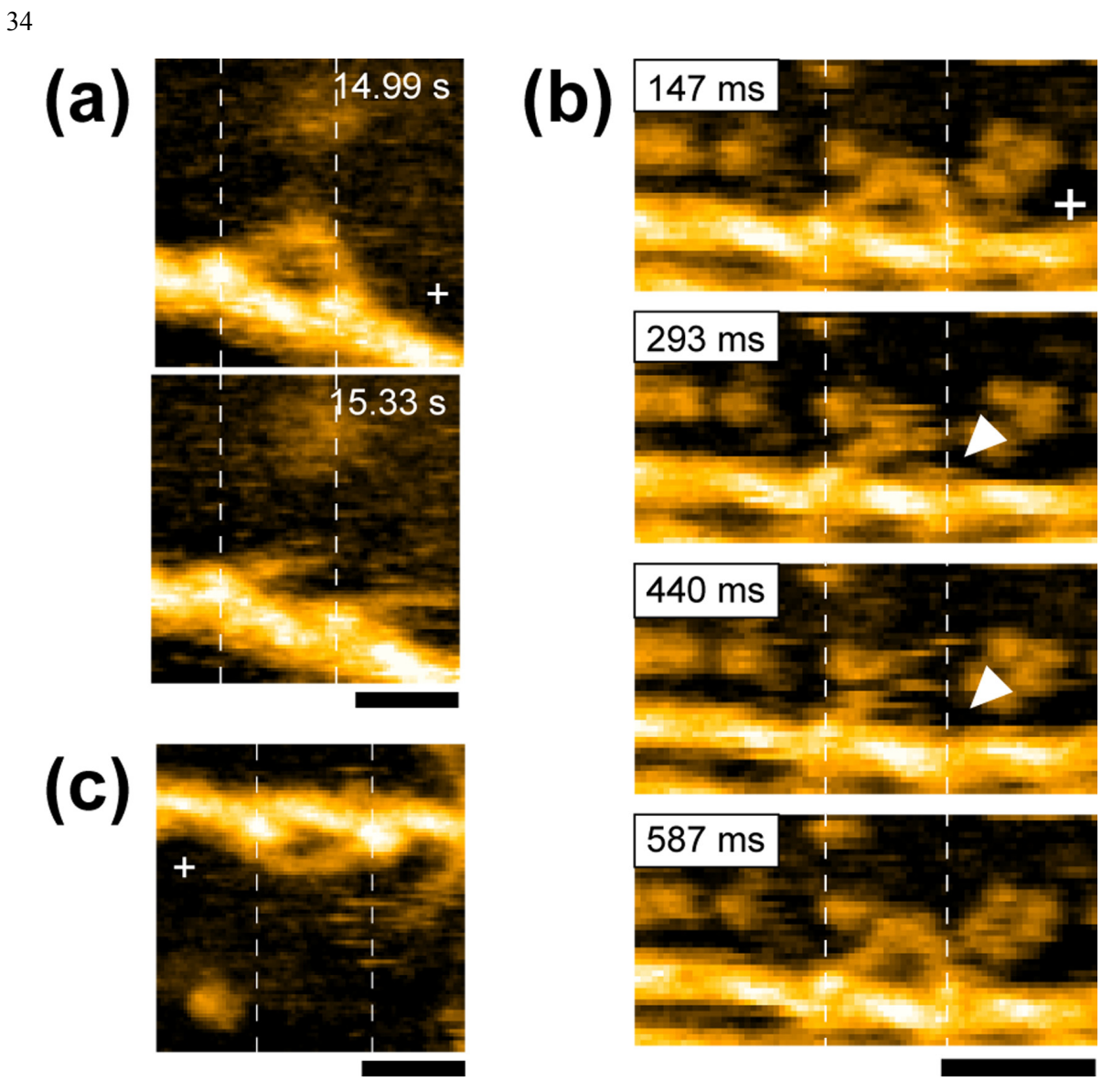

Fig. 4 
(a)

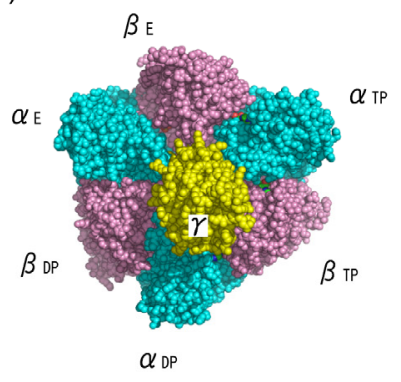

(b)

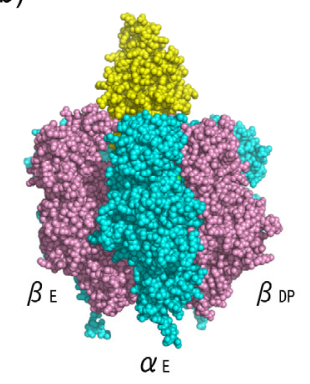

(c)

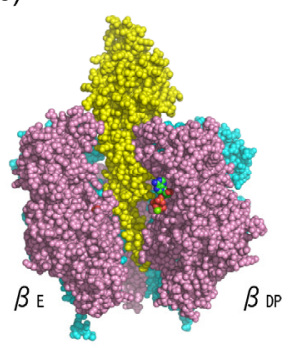

Fig. 5
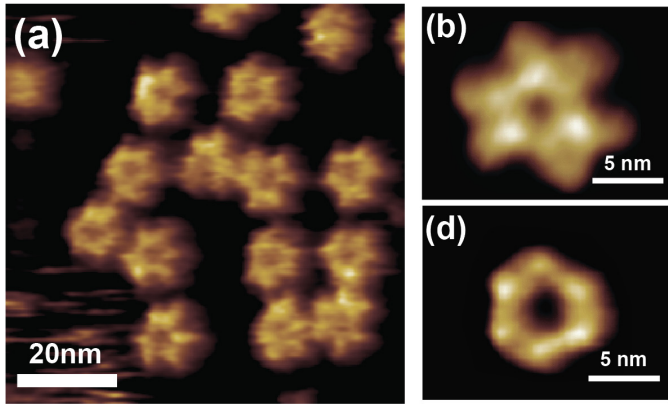

(d)
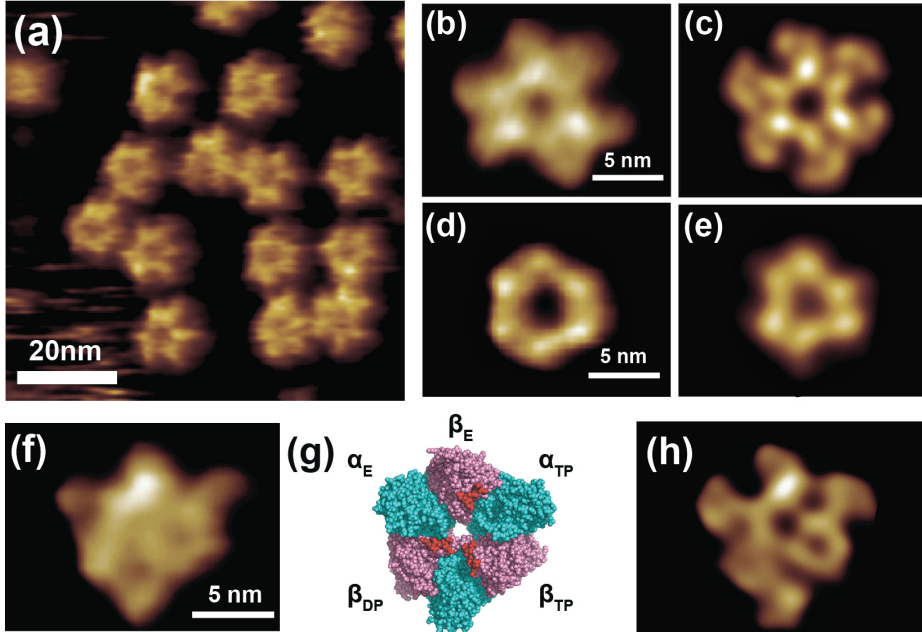

(g) $\alpha_{\mathrm{E}}$

$\begin{array}{lll}\boldsymbol{\beta}_{\mathrm{E}} & \\ \boldsymbol{\alpha}_{\mathrm{TP}} & \text { (h) }\end{array}$
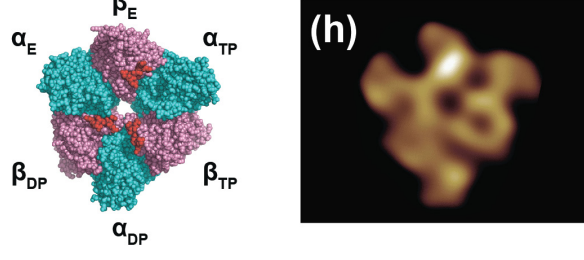

Fig. 6 
36

(a)

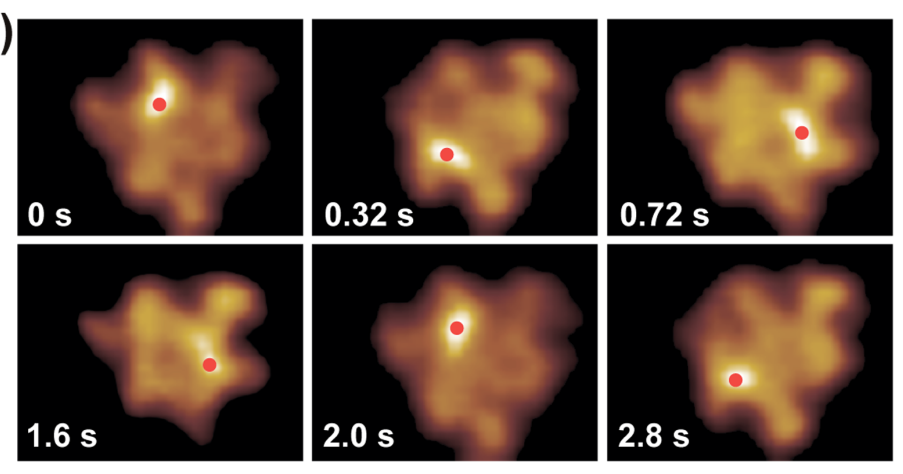

(b)

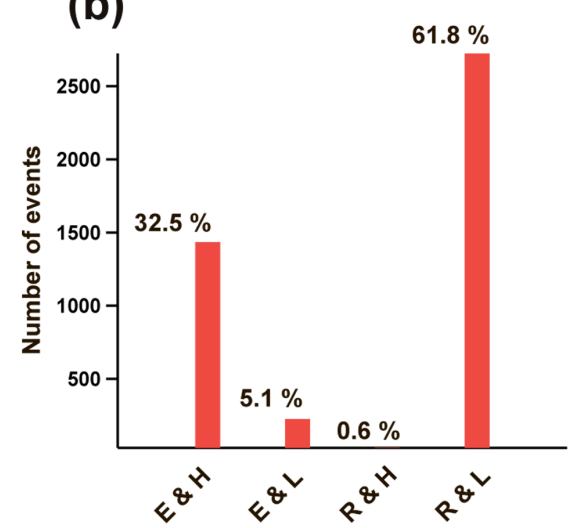

(d)

(c)

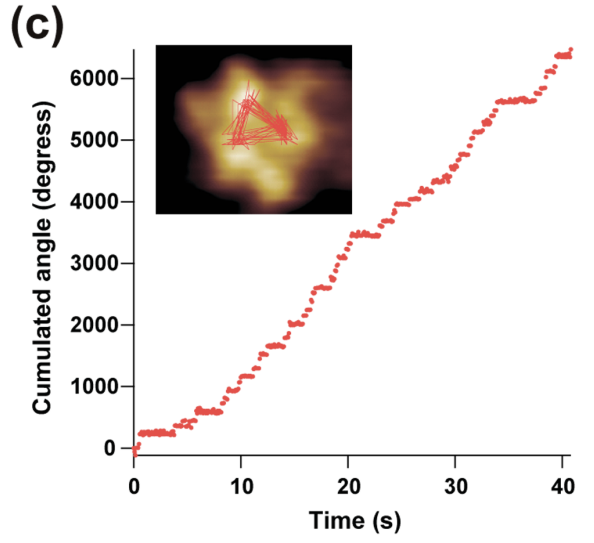

(e)
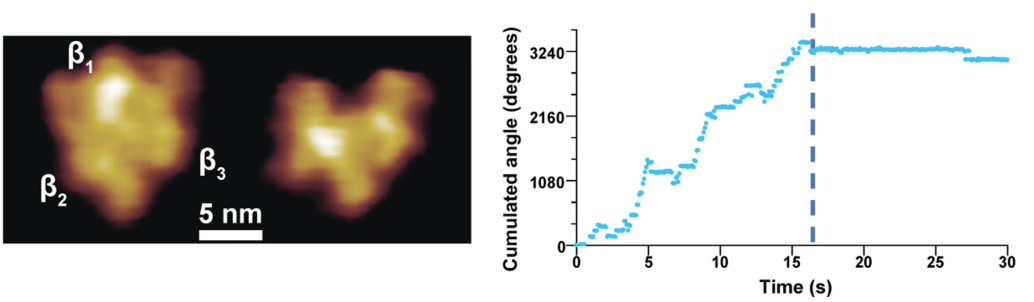

Fig. 7 
(a)
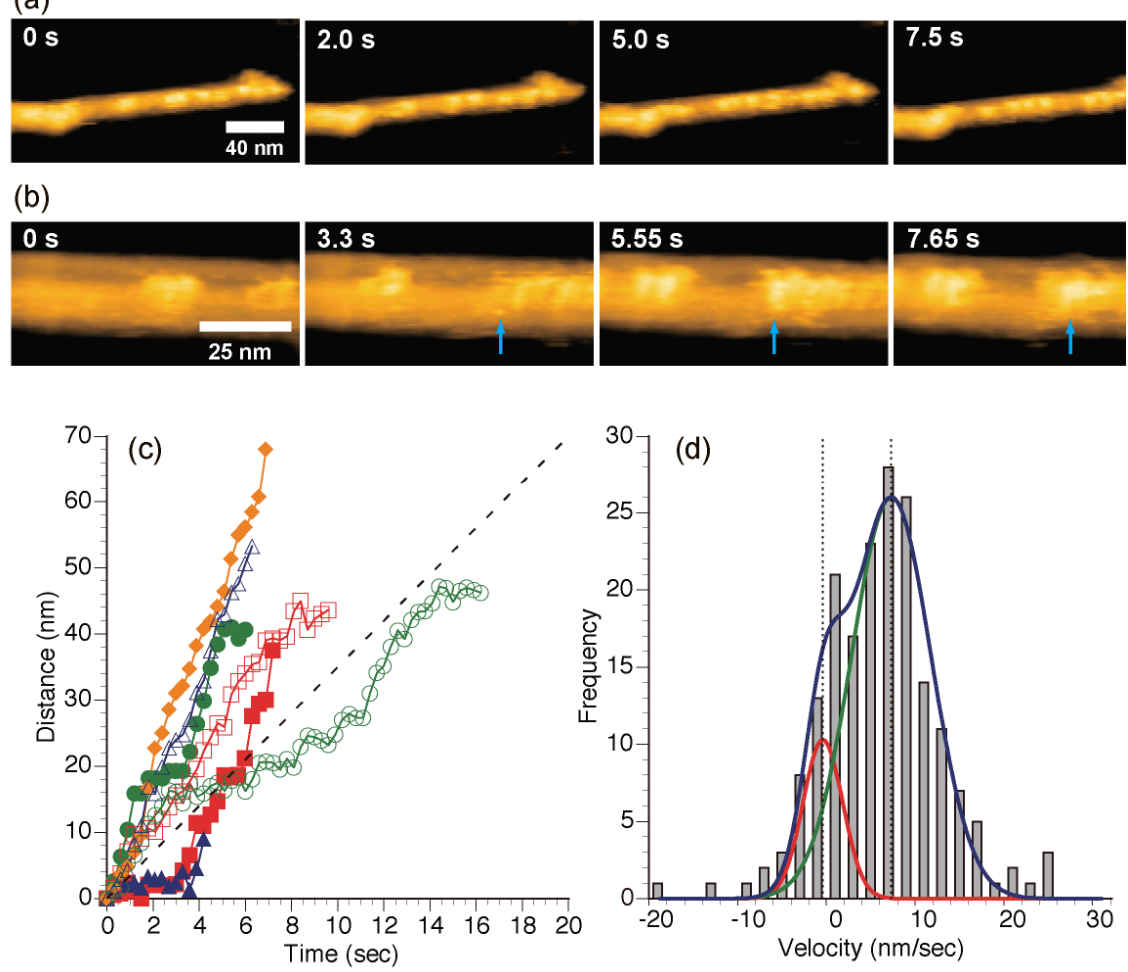

Fig. 8 

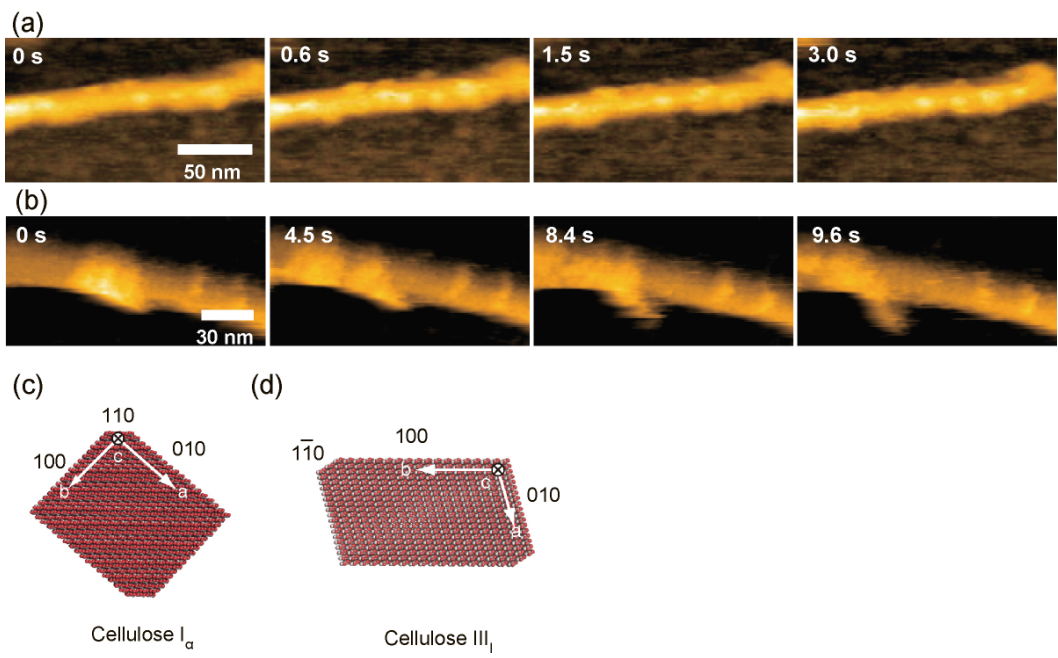

Fig. 9

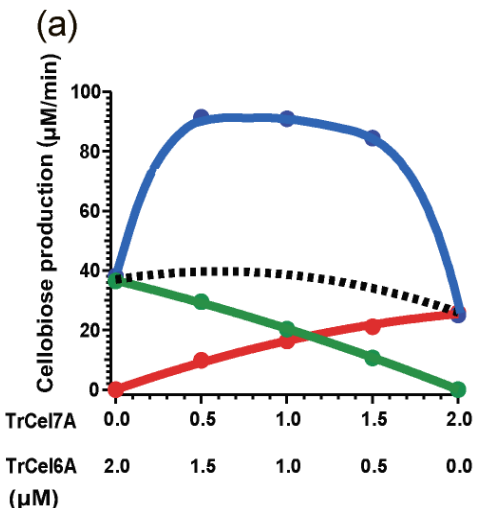

(b)

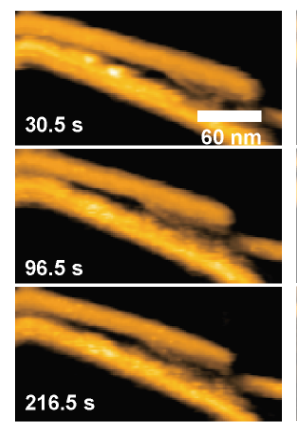

(c)

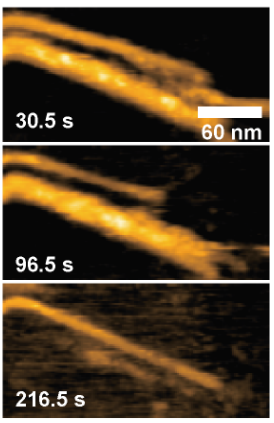

Fig. 10 